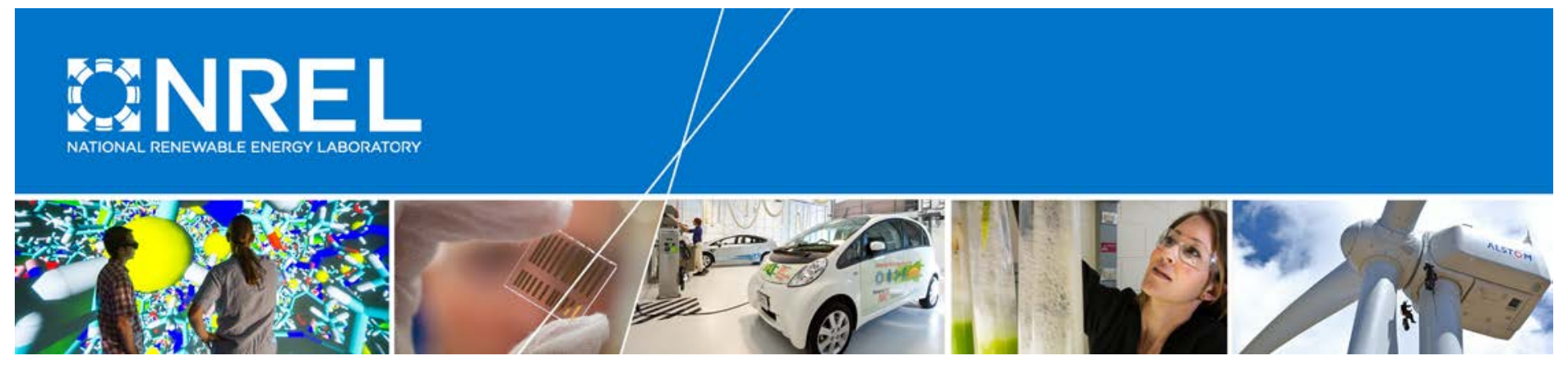

\title{
Impact of Market Behavior, Fleet Composition, and Ancillary Services on Revenue Sufficiency
}

Bethany Frew, Giulia Gallo, Gregory Brinkman, Michael Milligan, Kara Clark, and Aaron Bloom National Renewable Energy Laboratory

NREL is a national laboratory of the U.S. Department of Energy Office of Energy Efficiency \& Renewable Energy Operated by the Alliance for Sustainable Energy, LLC

This report is available at no cost from the National Renewable Energy Laboratory (NREL) at www.nrel.gov/publications.

Technical Report

NREL/TP-5D00-66076

June 2016

Contract No. DE-AC36-08G028308 


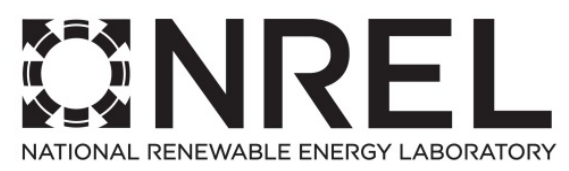

\section{Impact of Market Behavior, Fleet Composition, and Ancillary Services on Revenue Sufficiency}

Bethany Frew, Giulia Gallo, Gregory Brinkman, Michael Milligan, Kara Clark, and Aaron Bloom National Renewable Energy Laboratory

Prepared under Task No. WE14.9B01

NREL is a national laboratory of the U.S. Department of Energy Office of Energy Efficiency \& Renewable Energy Operated by the Alliance for Sustainable Energy, LLC

This report is available at no cost from the National Renewable Energy Laboratory (NREL) at www.nrel.gov/publications.

National Renewable Energy Laboratory 15013 Denver West Parkway Golden, CO 80401 303-275-3000 • www.nrel.gov
Technical Report

NREL/TP-5D00-66076

June 2016

Contract No. DE-AC36-08G028308 


\section{NOTICE}

This report was prepared as an account of work sponsored by an agency of the United States government. Neither the United States government nor any agency thereof, nor any of their employees, makes any warranty, express or implied, or assumes any legal liability or responsibility for the accuracy, completeness, or usefulness of any information, apparatus, product, or process disclosed, or represents that its use would not infringe privately owned rights. Reference herein to any specific commercial product, process, or service by trade name, trademark, manufacturer, or otherwise does not necessarily constitute or imply its endorsement, recommendation, or favoring by the United States government or any agency thereof. The views and opinions of authors expressed herein do not necessarily state or reflect those of the United States government or any agency thereof.

This report is available at no cost from the National Renewable Energy Laboratory (NREL) at www.nrel.gov/publications.

Available electronically at SciTech Connect http:/www.osti.gov/scitech

Available for a processing fee to U.S. Department of Energy and its contractors, in paper, from:

U.S. Department of Energy

Office of Scientific and Technical Information

P.O. Box 62

Oak Ridge, TN 37831-0062

OSTI http://www.osti.gov

Phone: 865.576.8401

Fax: 865.576.5728

Email: reports@osti.gov

Available for sale to the public, in paper, from:

U.S. Department of Commerce

National Technical Information Service

5301 Shawnee Road

Alexandria, VA 22312

NTIS http://www.ntis.gov

Phone: 800.553 .6847 or 703.605 .6000

Fax: 703.605.6900

Email: orders@ntis.gov 


\section{Acknowledgments}

We thank Paul Denholm and Ben Kroposki (National Renewable Energy Laboratory), Erik Ela (Electric Power Research Institute), and Chunlian (Julie) Jin (Electric Reliability Council of Texas) for their thoughtful reviews, comments, and suggestions. We especially thank Charlton Clark (U.S. Department of Energy) for his helpful review and for sponsoring this work. We are grateful for the editorial support from Katie Wensuc (National Renewable Energy Laboratory). This research was funded by the U.S. Department of Energy, Office of Energy Efficiency and Renewable Energy, Wind and Water Power Technologies Office under contract number DEAC36-08GO28308. Any and all errors are the sole responsibility of the authors. 


\section{List of Acronyms}

ATB

CAISO

CAPEX

$\mathrm{CC}$

CT

DAM

EIA

ERCOT

EUE

IC

LOLE

LOLH

MMBTU

MWh

NERC

NREL

ORDC

PNM

SPP

S\&S

SOM annual technology baseline

California Independent System Operator

capital expenditures

combined cycle

combustion turbine

day-ahead market

Energy Information Administration

Electric Reliability Council of Texas

expected unserved energy

internal combustion

loss of load expectation

loss of load hours

million British thermal units

megawatt-hour

North American Electric Reliability Corporation

National Renewable Energy Laboratory

operating reserve demand curve

peaker net margin

settlement point price

start-up and shutdown cost

ERCOT State of the Market Report 


\section{Abstract}

Revenue insufficiency, or the missing money problem, occurs when the revenues that generators earn from the market are not sufficient to cover both fixed and variable costs to remain in the market and/or justify investments in new capacity, which may be needed for reliability. The near-zero marginal cost of variable renewable generators further exacerbates these revenue challenges. Estimating the extent of the missing money problem in current electricity markets is an important, nontrivial task that requires representing both how the power system operates and how market participants behave.

This paper explores the missing money problem using a production cost model that represented a simplified version of the Electric Reliability Council of Texas (ERCOT) energy-only market for the years 2012-2014. We evaluate how various market structures - including market behavior, ancillary services, and changing fleet compositions - affect net revenues in this ERCOT-like system.

In most production cost modeling exercises, resources are assumed to offer their marginal capabilities at marginal costs. Although this assumption is reasonable for feasibility studies and long-term planning, it does not adequately consider the market behaviors that impact revenue sufficiency. In this work, we simulate a limited set of market participant strategic bidding behaviors by means of different sets of markups; these markups are applied to the true production costs of all gas generators, which are the most prominent generators in ERCOT. Results show that markups can help generators increase their net revenues overall, although net revenues may increase or decrease depending on the technology and the year under study. Results also confirm that conventional, variable-cost-based production cost simulations do not capture prices accurately, and this particular feature calls for proxies for strategic behaviors (e.g., markups) and more accurate representations of how electricity markets work.

The analysis also shows that generators face revenue sufficiency challenges in this ERCOT-like energy-only market model; net revenues provided by the market in all base markup cases and sensitivity scenarios (except when a large fraction of the existing coal fleet is retired) are not sufficient to justify investments in new capacity for thermal and nuclear power units. Overall, the work described in this paper points to the need for improved behavioral models of electricity markets to more accurately study current and potential market design issues that could arise in systems with high penetrations of renewable generation. 


\section{Table of Contents}

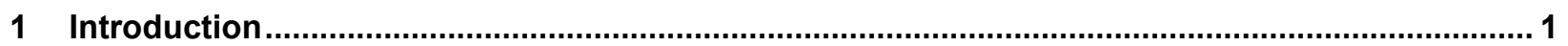

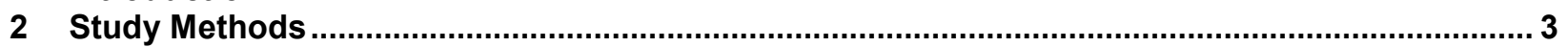

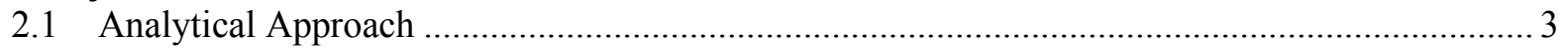

2.2 ERCOT-like System Production Cost Model ….................................................................... 3

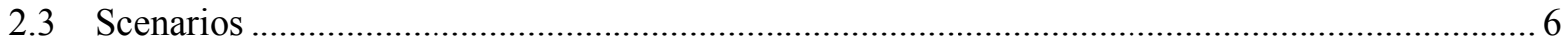

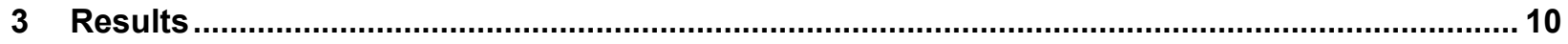

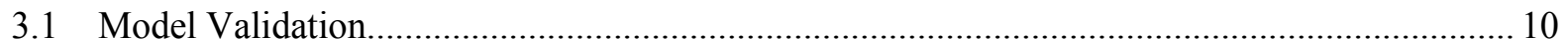

3.2 Impact of Market Behaviors on Production Costs, Revenues, and Generation .......................... 17

3.3 Sensitivity Analysis to Assess Revenue Sufficiency Challenges............................................. 21

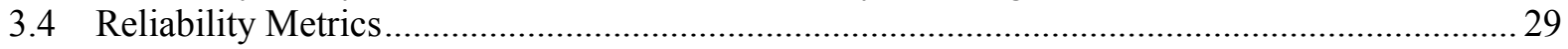

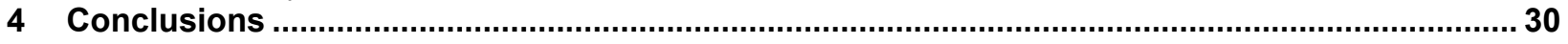

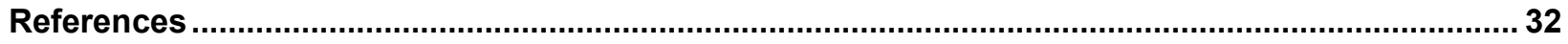

Appendix: Additional Benchmarking and Revenue Sufficiency Results ....................................... 35 


\section{List of Figures}

Figure 1. Production simulation model 2013 Benchmark scenario (0-40-80 markups) generator installed capacity (left) and annual generation mix (right) compared to historic reported EIA values 11

Figure 2. Annual generation mix for the 2013 Benchmark scenario 11

Figure 3. Day-ahead price duration curves averaged across all regions (magnified to show prices at or below \$100/MWh) for all 2013 markup scenarios and historic day-ahead SPPs from ERCOT...

Figure 4. Regional day-ahead energy price duration curves (magnified to show prices at or below \$100/MWh) for the 2013 Benchmark scenario and historic day-ahead SPPs from ERCOT. 13

Figure 5. Regional average hourly day-ahead energy price by hour of day for the 2013 Benchmark scenario compared to the historic day-ahead SPPs from ERCOT ....................................... 14

Figure 6. Regional average hourly day-ahead energy price by month for the 2013 Benchmark scenario compared to the historic day-ahead SPPs from ERCOT.................................................. 15

Figure 7 Ancillary service price duration curves averaged across all regions (magnified to show prices at or below \$100/MWh) for 2013 Benchmark scenario and historic day-ahead ancillary service prices from ERCOT

Figure 8. Normalized annual production cost differences among the 2013 Benchmark, No Markups, and Flat Markups scenarios .....

Figure 9. Normalized annual revenue differences among the 2013 Benchmark, No Markups, and Flat

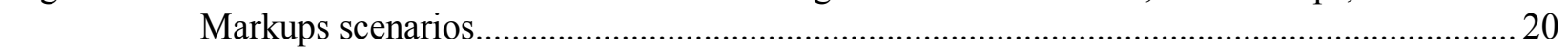

Figure 10. Normalized annual net revenue differences among the 2013 Benchmark, No Markups, and Flat

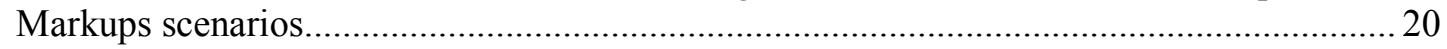

Figure 11. Total annual hours of operation differences among the 2013 Benchmark, No Markups, and Flat

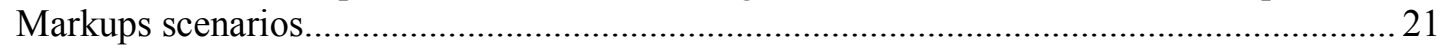

Figure 12. Total annual generation differences among the 2013 Benchmark, No Markups, and Flat

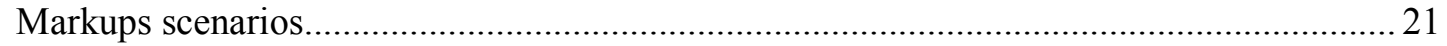

Figure 13. Net revenue averaged across each daily hour bin for the 2013 Benchmark scenario............... 23

Figure 14. Net revenue averaged across all hours within each month for the 2013 Benchmark scenario.. 23

Figure 15. Benchmark scenarios net revenues with and without start-up and shutdown costs (S\&S) and compared to annualized investment costs from NREL's ATB and ERCOT's State of the

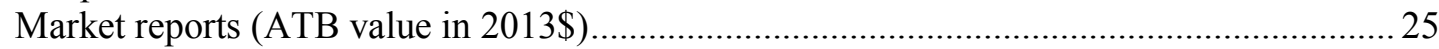

Figure 16. PNM for the 2012-2014 Benchmark scenarios.................................................................. 26

Figure 17. Price duration curves averaged across all regions (magnified to show prices at or below $\$ 100 / \mathrm{MWh})$ for the 2013 Benchmark and all sensitivity scenarios .................................... 26

Figure 18. Net revenues for the 2013 Benchmark and sensitivity scenarios and ATB annualized

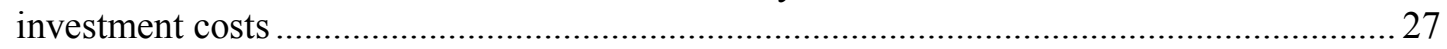

Figure 19. Net revenues difference from the 2013 Benchmark scenario.............................................. 27

Figure 20. Total revenues for the 2013 Benchmark and Flex Up scenarios .............................................. 28

Figure 21. Day-ahead price duration curves averaged across all regions (magnified to show prices at or below \$100/MWh) for all 2012 markup scenarios and historic day-ahead SPPs from

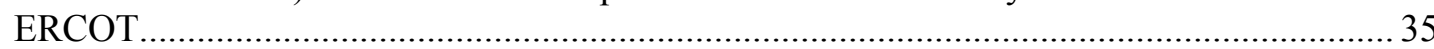

Figure 22. Day-ahead price duration curves averaged across all regions (magnified to shows prices at or below \$100/MWh) for all 2014 markup scenarios and historic day-ahead SPPs from

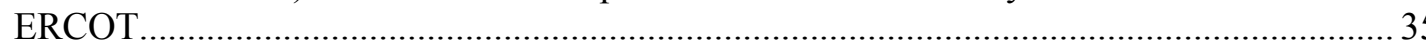




\section{List of Tables}

Table 1. ERCOT-like Production Simulation Model Generator Fleet (MW) ........................................... 5

Table 2. Natural Gas Prices (\$/MMBTU) by Month and Year................................................................ 5

Table 3. Markup Scenarios Evaluated for Each Year from 2012-2014 _.................................................. 7

Table 4. Sensitivity Scenarios Evaluated from the Benchmark Case for Each Year from 2012-2014 ........ 7

Table 5. Total Wind Capacity (MW) in the Benchmark Scenarios and Scenarios with High Wind (High

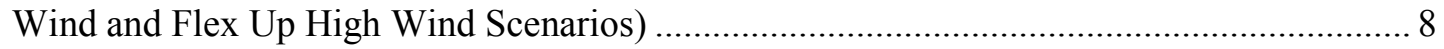

Table 6. Load and Wind for the Benchmark Scenarios by Year ….................................................. 8

Table 7. Production Simulation Model Reserve Requirements ........................................................... 9

Table 8. Energy Price Validation for the Middle 80\% of All Hours for the 2012-2014 Benchmark

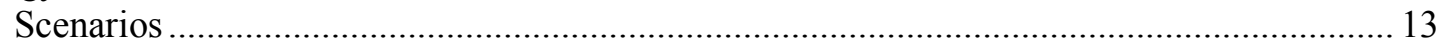

Table 9. Percent Increase in Day-Ahead Energy Prices from Historic ERCOT Data for the Middle 80\% of

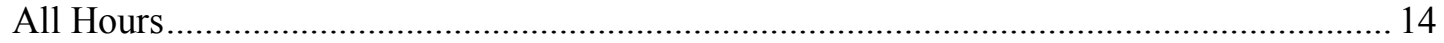

Table 10. Load, Wind, and Natural Gas Summary Inputs for the Benchmark Scenarios by Year............ 15

Table 11. Average Ancillary Service Prices for the Middle 80\%, Top 10\%, and Bottom 10\% of All Hours from the 2012-2014 Benchmark Scenarios and Historic Day-Ahead Ancillary Service Prices

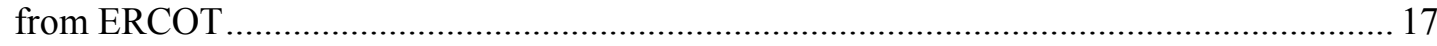

Table 12. Difference in Total Production Costs among Select 2013 Markup Scenarios .......................... 18

Table 13. Price, Revenue, and Operation Summary for the Benchmark Scenarios.................................. 22

Table 14. Frequency of Penalty Price among All Four Regions............................................................. 29

Table 15. Benchmark Scenarios Net Revenues with and without Start-up and Shutdown Costs (S\&S) and Compared to Annualized Investment Costs from the NREL's ATB and ERCOT's State of

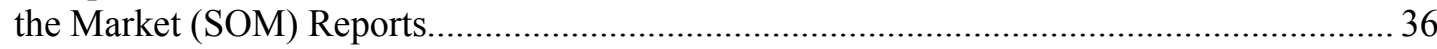




\section{Introduction}

Restructured markets for electricity have been adopted around the world as a means to encourage competition in the supply of electricity. These markets have evolved substantially since their creation in the early 1990s, and they continue to evolve as shortcomings in market design are identified. A key motivation behind these markets is to provide incentives for producers to produce electricity efficiently and to promote competition (Cramton 2003). To the extent that economic efficiency could be attained, consumers would benefit from lower electricity prices that result from a competitive market.

The emergence of these markets represents a significant change from the historical cost-ofservice regulation of the electricity industry. This regulation was motivated by several economic concerns, including the market power that results from monopoly or near-monopoly providers, which naturally results from significant economies of scale, both in generation and in transmission. The evolution to markets represents the hypothesis that generation economies of scale were no longer as significant as once believed, but transmission is generally recognized as a product that would be difficult or impossible to provide by the usual competitive markets.

The introduction of electricity markets did not represent a full break from the regulated past. Although wholesale power generation is part of new market designs, retail load-serving entities in the United States are generally regulated. The historical practice of regulating prices, along with the idea that electricity is an essential service, has motivated regulators to strive for price stability at both the retail and the wholesale levels. The inability of prices to adjust to reflect market conditions is a sufficient condition for some degree of market failure in electricity markets, i.e., the inability of buyers and sellers to jointly adjust their buying and selling decisions to account for abundance or scarcity.

Classic market economics dictate that in competitive markets prices perform a rationing function that ensures efficient levels of supply and demand. This is not possible in electricity markets because of a combination of administered prices and administered price caps (which were set to control market power; see Cramton [2003]) in wholesale electricity markets. As a result, demand for electricity will sometimes exceed supply, potentially posing reliability issues for system operators as well as regulatory issues for market designers.

Electricity markets do not explicitly account for reliability requirements unless there is a reliability component either in electricity pricing or as some type of reliability-based target (Ela et al. 2014; Cramton et al. 2013). This means that electricity markets by themselves can only accidentally achieve an administered reliability target. During periods of shortage, prices can spike significantly, but price caps may interfere. The result is that resources that may be needed for only a short time of the year must recover both capital and operational costs in a small number of hours or days, and therefore they may not have the opportunity to earn sufficient revenue to remain in the market (Cramton and Stoft 2006).

Variable generation, such as solar and wind power, have been found, both in power system economic studies and in practice (Keane et al. 2011; Milligan et al. 2012; Gallo 2016a) to reduce wholesale electricity prices during periods of high variable generation output because of their near-zero marginal costs. This price suppression, along with the market's inability to account for 
reliability, may increase the missing money problem for some generators (i.e., peakers) that are needed to ensure resource adequacy but do not earn sufficient revenue to remain in the market (Cramton and Stoft 2006, Ecco International 2015, Levin and Botterud 2015). To the extent that a missing money problem already exists in the bulk system, high penetrations of variable generation may create a merit-order effect that pushes more expensive resources up (or off) the dispatch stack (Gallo 2016b). The remaining resources will run at lower capacity factors, and both of these impacts - price reduction and energy sales reduction - will erode the revenue earned by many plants. In an electricity market that has revenue sufficiency challenges prior to the introduction of large-scale variable generation development, high levels of wind and/or solar energy will likely exacerbate this issue.

In this paper, we explore the extent of the missing money problem with high penetrations of wind generation using a production cost model based on the Electric Reliability Council of Texas (ERCOT). ERCOT is an energy only market and does not rely on capacity markets or payments to encourage new generation technology; other energy-only markets include the Alberta Electric System Operator and Australia's National Electricity Market. The modeling assumptions as well as the scenarios and sensitivities performed are discussed in Section 2. Because production simulation models have difficulty calculating prices that match those found in operating markets, we perform a pricing validation and adjustment process to ensure that our model captures prices that are comparable to historic values (presented in Section 3). Also in Section 3, we present results for our various study scenarios that reveal the existence of the missing money problem in nearly all cases. Conclusions are presented in Section 4. 


\section{Study Methods}

\subsection{Analytical Approach}

We used PLEXOS, Energy Exemplar's commercial production cost model, to simulate the dayahead operation of an ERCOT-like system on an hour-by-hour basis for an entire year. This allowed us to model the hourly chronological dispatch and power transfer across the power grid for different sets of conditions including simplified market participant behaviors, variable wind generation, ancillary service markets, and changes in generator fleet compositions.

PLEXOS $^{1}$ is a mixed integer programming tool that can perform a variety of optimization-based functions and simulations of energy markets. In this work, we used PLEXOS to solve for the least-cost system-wide day-ahead dispatch. For simplicity, we did not model real-time operations; future work will include this common production simulation component, ideally at a subhourly resolution. The day-ahead model was based on historic hourly load and wind profiles and included an additional one day look-ahead period for modeling foresight. Because wind and load forecasts were not used, the model did not explicitly capture uncertainty due to forecast errors. Variability, however, was captured within each of the respective data sets. Four types of operating reserves were modeled: regulation up, regulation down, spinning, and non-spinning. An additional flexibility reserve was included in select sensitivity scenarios to capture the additional variability and uncertainty burden from wind resources (Lew et al. [2013]). PLEXOS co-optimized energy and reserves during the simulations. We ran the model zonally for the four ERCOT load regions, thereby ignoring intra-zonal transmission constraints, and any corresponding local congestion. To create a modeling framework for comparison among scenarios, we modeled 3 years of operating conditions (2012-2014) and benchmarked the model against historic ERCOT prices (ERCOT 2012a-2014a), reported Energy Information Administration (EIA) values (EIA 2013a and 2013b), and relevant ERCOT State of the Market reports (Potomac Economics 2013, 2014, and 2015).

The analysis focused on specific outputs from the production simulations such as total system production cost, regional energy prices, generation capacity and dispatch by category, generator net revenues, and hours of operation. The relative price and revenue differences among the scenarios and the different markup values were the primary variables of interest for this study. Revenues from both energy and ancillary service markets were included, whereas net revenue was the revenue minus operational costs. ${ }^{2}$ Net revenues were compared to annualized investment costs from both ERCOT and the National Renewable Energy Laboratory's (NREL's) Annual Technology Baseline (ATB) data set (Blair et al. 2015) to estimate revenue sufficiency. These numbers were for comparison purposes only; precise estimates for revenue sufficiency would require understanding the investment costs for specific projects, both for existing and new generating facilities.

\subsection{ERCOT-like System Production Cost Model}

The PLEXOS model used for this study was based on the model and data from Townsend (2013). This provided the generator fleet cost and performance data, which were originally taken

\footnotetext{
${ }^{1}$ PLEXOS is one of several commercially available production cost models. A list of publications that describe previous analyses performed with this tool is available at http://energyexemplar.com/publications/

${ }^{2}$ Operational costs include fuel costs and variable operations and maintenance costs but not start-up costs.
} 
from the ERCOT Long-Term Study (2011) and Cohen (2012) and included generators in operation in 2010 plus additional generators that ERCOT expected (at the time) to be built to meet electricity demand growth. Private network generators were also included in this database. Generator heat rate information in this model came from the U.S. Environmental Protection Agency's Continuous Emission Monitoring System (CEMS) data. ${ }^{3}$ We made a number of changes to this model and data set, as detailed below, to improve model fidelity for comparison to ERCOT market outcomes and to model several years of actual market conditions.

For a better comparison to historical ERCOT operations, we disaggregated the original singlezone model into a four-zone model to represent the zones (North, South, West, and Houston) that are reported in the ERCOT State of the Market reports (Potomac Economics 2013, 2014, 2015). Transmission limits between the zones were based on published estimates in multiple ERCOT market and transmission reports (Potomac Economics 2004, 2013; ERCOT 2013a). In PLEXOS, we used a zonal market approach rather than a nodal market representation. A zonal market approach cannot model the actual ERCOT nodal congestion; however, this model can represent aggregated congestion that is seen in the real ERCOT system. The primary interface with congestion is from the West region, which has the bulk of the wind generation and significantly less load. Generators in the original model were assigned to the four zones based on the Velocity Suite (Ventyx 2015) data, which included generator names and locations. Historic hourly load data was collected from ERCOT and then assigned to each zone based on the reported control area. $^{4}$

The original database included more coal and natural gas generating capacity than what existed in ERCOT in 2013. To avoid modeling a system that had unrealistically high generating capacity (which could model prices and revenues that are too low), we scaled the coal and gas generator capacities to approximately match the 2013 State of the Market Report (Potomac Economics 2014). Coal generation capacity was reduced by $20 \%$ and natural gas by $10 \%$. Some of the generating capacity in the original data set was not operating in 2013, and other generators had capacity estimates that were too high. Note that the resulting capacities may not exactly reflect current values in the ERCOT system.

Hourly ERCOT-wide wind generation profiles were published by ERCOT for the years 2012 $2014 .{ }^{5}$ We disaggregated these profiles into inland resources (assumed to all be located in the West zone) and coastal resources (assumed to all be located in the South zone) based on hourly time series of hypothetical wind sites from AWS Truepower (2015). Each site was assigned to a zone based on the county in which it is located. The historic hourly ERCOT-wide wind production was then split between the West and South regions based on the relative contribution of total wind output from each region for each hour. Table 1 shows the capacity of all generator types in each region of the model. Table 2 shows the natural gas price assumptions. Wind generation was assumed to offer energy for no cost into the market. Ancillary services modeled included spinning and non-spinning reserves and regulation up and regulation down reserves, as

\footnotetext{
${ }^{3}$ See https://www3.epa.gov/ttnemc01/cem.html.

${ }^{4}$ See http://www.ercot.com/gridinfo/load/load hist/index.html.

${ }^{5}$ See "Hourly Aggregated Wind Output" at http://www.ercot.com/gridinfo/generation/index.html.
} 
described in Table 7 in Section 2.3. Wind generation was not allowed to provide any ancillary services.

Table 1. ERCOT-like Production Simulation Model Generator Fleet (MW)

\begin{tabular}{llllll}
\hline & North & South & Houston & West & $\begin{array}{l}\text { ERCOT } \\
\text { Total }\end{array}$ \\
\hline Coal & 8,873 & 4,586 & 2,070 & 517 & $\mathbf{1 6 , 0 4 6}$ \\
\hline Biomass & 147 & - & - & - & $\mathbf{1 4 7}$ \\
\hline Hydro & 286 & 429 & - & - & $\mathbf{7 1 5}$ \\
\hline Gas_Boiler & 4,844 & 3,622 & 2,791 & - & $\mathbf{1 1 , 2 5 6}$ \\
\hline Gas_CC & 12,743 & 9,099 & 6,844 & 2,890 & $\mathbf{3 1 , 5 7 5}$ \\
\hline Gas_IC & - & 204 & - & 204 & $\mathbf{4 0 8}$ \\
\hline Gas_CTc & 827 & 1,218 & 1,478 & 1,282 & $\mathbf{4 , 8 0 4}$ \\
\hline Nuclear & 2,566 & - & 2,566 & - & $\mathbf{5 , 1 3 2}$ \\
\hline 2012 Wind & - & 1,393 & - & 8,413 & $\mathbf{9 , 8 0 5}$ \\
\hline 2013 Wind & - & 1,644 & - & 9,421 & $\mathbf{1 1 , 0 6 4}$ \\
\hline 2014 Wind & - & 2,093 & - & 9,052 & $\mathbf{1 1 , 1 4 5}$ \\
\hline
\end{tabular}

${ }^{\mathrm{a}} \mathrm{CC}=$ combined cycle

${ }^{\mathrm{b}} \mathrm{IC}=$ internal combustion

${ }^{\mathrm{c}} \mathrm{CT}=$ combustion turbine

Table 2. Natural Gas Prices (\$/MMBTU) by Month and Year

\begin{tabular}{llll}
\hline Month & 2012 & 2013 & 2014 \\
\hline January & 2.67 & 3.33 & 4.71 \\
\hline February & 2.43 & 3.33 & 4.58 \\
\hline March & 2.46 & 3.81 & 4.59 \\
\hline April & 2.95 & 4.17 & 4.05 \\
\hline May & 2.84 & 4.04 & 3.91 \\
\hline June & 2.85 & 3.83 & 3.92 \\
\hline July & 3.32 & 3.62 & 3.78 \\
\hline August & 3.54 & 3.43 & 4.12 \\
\hline September & 3.34 & 3.62 & 3.48 \\
\hline October & 2.51 & 3.68 & 6.00 \\
\hline November & 2.17 & 3.64 & 4.90 \\
\hline December & 1.95 & 4.24 & 4.66 \\
\hline
\end{tabular}




\subsection{Scenarios}

To improve on traditional production cost modeling methods and produce more accurate price results, we simulated market behaviors by applying a variety of bid-cost markups (described below). These markups were used to determine which set yields prices that best match observed market conditions in the years 2012-2014. In this study, we analyzed the results of these different markups to help understand the impacts of abstract market bidding behaviors that can be seen as economic withholding strategies on energy prices. This is a proxy to represent actual strategic bidding that occurs by small generators in the ERCOT system; such flexibility in their energy bidding behavior is permitted by the so-called Small Fish Rule. ${ }^{6}$ Our work is a proxy for what could happen if natural gas generators, regardless of their size, have the opportunity to bid with this allowance. This study did not include any dynamic strategic behavior that changes over time, such as agent-based models (see Gallo [2016a]). However, the strategic bidding behaviors modeled in this study can shed light on the importance of including more realistic representations of market behaviors - behaviors that can impact both market outcomes and system reliability.

The Benchmark scenario for each year was created by applying different sets of markups to the true production costs of gas generators. Similar to the method used in Townsend (2013), we applied three different markup percentages to the first third, middle third, and last third of the offer curve. These markups bins corresponded to the three bins characterizing the heat rate curve, whose break points were assigned by the model such that each unit's generation range was divided into three evenly sized bands. In some cases, the markups were identical throughout the offer curve (a "flat" markup); in other cases, they increased toward the higher levels of the offer curve (a "graduated" markup). We refer to the markups by the set of percentage increases in the offers. For example, a 0-40-80 markup would include no markup on the first third of the offer curve, a $40 \%$ markup on the middle, and an $80 \%$ markup on the highest third of the offer curve. True production cost offer curves are based on fuel costs and variable operations and maintenance costs. We tested no markups (0-0-0), flat markups (40-40-40), 0-40-80 markups (used by Townsend [2013]), 0-40-120 markups, and 0-40-200 markups. The markups that provided the best day-ahead price match with historic day-ahead market (DAM) prices (ERCOT 2012-2014) for each year were chosen as the Benchmark scenarios (see Table 3).

It is important to note several study limitations. For example, the price outputs from the PLEXOS model reflect day-ahead values for each of the four zones, and the ERCOT data used for the price validation represent spatially-averaged day-ahead values across numerous resource sites within each zone (or "trading hub"). Differences in how each result is calculated could result in discrepancies in the price outputs. We also assumed that markups were applied to the natural gas generators in a constant fashion across all hours and days of the year; actual behavior would be far more dynamic, and such time-varying aspects will be included in future work. In addition, this model does not account for self-scheduled units, maintenance, forced outage rates, and demand-side participation, although the next phases of this work will. In particular,

\footnotetext{
${ }^{6}$ The Small Fish Rule is defined by a provision of the Public Utility Commission of Texas Substantive Rules that deems any electricity-generating entity controlling less than $5 \%$ of the total installed generation capacity in ERCOT as not having ERCOT-wide market power. The rule protects small new entrants in the generation market from claims of market power abuse, providing the opportunity for a sufficient return on investment and removing potential uncertainty that might otherwise discourage the entry of new generation (Anderson 2015).
} 
maintenance and forced outage rates will effectively reduce the availability of generating capacity, which could significantly impact revenues.

Table 3. Markup Scenarios Evaluated for Each Year from 2012-2014

\begin{tabular}{|c|c|c|c|c|}
\hline $\begin{array}{l}\text { Scenario } \\
\text { Name }\end{array}$ & $\begin{array}{l}\text { Offer Bid } \\
\text { Markup in } 1^{\text {st }} \\
\text { Heat Rate Bin }\end{array}$ & $\begin{array}{l}\text { Offer Bid } \\
\text { Markup in } 2^{\text {nd }} \\
\text { Heat Rate Bin }\end{array}$ & $\begin{array}{l}\text { Offer Bid } \\
\text { Markup in } 3^{\text {rd }} \\
\text { Heat Rate Bin }\end{array}$ & Notes \\
\hline No Markups & 0 & 0 & 0 & $\begin{array}{l}\text { Generator offer bids reflect true } \\
\text { production costs }\end{array}$ \\
\hline $\begin{array}{l}40-40-40 \\
\text { Markups }\end{array}$ & $40 \%$ & $40 \%$ & $40 \%$ & Flat markups \\
\hline $0-40-80$ & 0 & $40 \%$ & $80 \%$ & Least steep graduated markups \\
\hline $0-40-120$ & 0 & $40 \%$ & $120 \%$ & $\begin{array}{l}\text { Selected as the Benchmark } \\
\text { scenario for } 2012 \text { and } 2013\end{array}$ \\
\hline $0-40-200$ & 0 & $40 \%$ & $200 \%$ & $\begin{array}{l}\text { Steepest graduated markups; } \\
\text { selected as the Benchmark } \\
\text { scenario for } 2014\end{array}$ \\
\hline
\end{tabular}

Three additional sets of assumptions were used to create four sensitivity scenarios, as summarized in Table 4: High Wind, Flex Up, Flex Up High Wind, and Retire 4GW of Coal. The additional wind capacity included in the High Wind and Flex Up High Wind scenarios consisted of the hypothetical sites from the AWS data previously described. The total wind capacities in the Benchmark and High Wind scenarios are shown in Table 5. The annual penetration level of wind in the Benchmark scenarios is approximately $10 \%$, and it grows to approximately $20 \%$ in the High Wind and Flex Up High Wind scenarios, as shown in Table 6.

Table 4. Sensitivity Scenarios Evaluated from the Benchmark Case for Each Year from 2012-2014

\begin{tabular}{|c|c|c|c|c|}
\hline $\begin{array}{l}\text { Sensitivity } \\
\text { Scenario }\end{array}$ & Wind Capacity & $\begin{array}{l}\text { Flexible } \\
\text { Reserve }\end{array}$ & $\begin{array}{l}\text { Coal } \\
\text { Retirement }\end{array}$ & Notes \\
\hline High Wind & High Wind & Benchmark & Benchmark & $\begin{array}{c}\text { Roughly double the ERCOT-wide } \\
\text { wind penetration relative to } \\
\text { Benchmark }\end{array}$ \\
\hline Flex Up & Benchmark & $\begin{array}{l}\text { Flex Up } \\
\text { reserve } \\
\text { requirement }\end{array}$ & Benchmark & \\
\hline $\begin{array}{c}\text { Flex Up High } \\
\text { Wind }\end{array}$ & High Wind & $\begin{array}{l}\text { Flex Up } \\
\text { reserve } \\
\text { requirement }\end{array}$ & Benchmark & \\
\hline $\begin{array}{l}\text { Retire 4GW } \\
\text { Coal }\end{array}$ & Benchmark & Benchmark & $\begin{array}{l}\text { North and } \\
\text { South zones }\end{array}$ & $\begin{array}{c}\text { Retire approximately } 23 \% \text { of } \\
\text { Base coal fleet }\end{array}$ \\
\hline
\end{tabular}


Table 5. Total Wind Capacity (MW) in the Benchmark Scenarios and Scenarios with High Wind (High Wind and Flex Up High Wind Scenarios)

\begin{tabular}{ccccccc}
\hline & \multicolumn{3}{c}{ Benchmark } & \multicolumn{3}{c}{ High Wind } \\
\hline & South & West & ERCOT Total & South & West & ERCOT Total \\
$\mathbf{2 0 1 2}$ & 1,393 & 8,413 & $\mathbf{9 , 8 0 5}$ & 4,388 & 15,521 & $\mathbf{1 9 , 9 0 8}$ \\
$\mathbf{2 0 1 3}$ & 1,644 & 9,421 & $\mathbf{1 1 , 0 6 4}$ & 4,638 & 16,529 & $\mathbf{2 1 , 1 6 7}$ \\
$\mathbf{2 0 1 4}$ & 2,093 & 9,052 & $\mathbf{1 1 , 1 4 5}$ & 5,088 & 16,160 & $\mathbf{2 1 , 2 4 8}$ \\
\hline
\end{tabular}

Table 6. Load and Wind for the Benchmark Scenarios by Year

\begin{tabular}{llllllll}
\hline & $\begin{array}{l}\text { Load } \\
\text { (TWh) }\end{array}$ & $\begin{array}{l}\text { Wind } \\
\text { (GW) }\end{array}$ & $\begin{array}{l}\text { Wind } \\
\text { (TWh) }\end{array}$ & $\begin{array}{l}\text { Wind \% } \\
\text { Load }\end{array}$ & $\begin{array}{l}\text { High } \\
\text { Wind } \\
\text { (GW) }\end{array}$ & $\begin{array}{l}\text { High } \\
\text { Wind } \\
\text { (TWh) }\end{array}$ & $\begin{array}{l}\text { High } \\
\text { Wind \% } \\
\text { Load }\end{array}$ \\
\hline $\mathbf{2 0 1 2}$ & 325 & 9.81 & 29 & $9.0 \%$ & 19.91 & 64 & $19.8 \%$ \\
\hline $\mathbf{2 0 1 3}$ & 332 & 11.06 & 33 & $9.9 \%$ & 21.17 & 67 & $20.2 \%$ \\
$\begin{array}{l}\text { \% Increase } \\
\text { from 2012 }\end{array}$ & $2 \%$ & & $12 \%$ & & & $4 \%$ & \\
\hline $\mathbf{2 0 1 4}$ & 340 & 11.14 & 36 & $10.6 \%$ & 21.25 & 71 & $21.0 \%$ \\
\hline $\begin{array}{l}\text { \% Increase } \\
\text { from 2013 }\end{array}$ & $3 \%$ & & $10 \%$ & & & $6 \%$ & \\
\hline
\end{tabular}

Two sensitivity scenarios-Flex Up and Flex Up High Wind - included an additional reserve requirement as a proxy for that proposed by Midcontinent Independent System Operator and California Independent System Operator (CAISO). ${ }^{7}$ These are intended to address the variability and uncertainty from wind resources and may also impact revenue sufficiency. This flexibility reserve requirement varies by hour, based on the load and wind values, and only the reserve requirements resulting from an over-prediction of wind production (i.e., flexible reserve in the "up" direction) were included. The method for calculating this was described by Lew et al. (2013) in the Western Wind and Solar Integration Study Phase 2. The average flexibility reserve requirement by scenario as well as the four constant reserve requirements are summarized in Table 7. The offer bids assumed for these reserve products in our PLEXOS model are also shown in the note associated with this table. Unlike other generator data, information related to an individual generator's ability to provide reserves is not publicly available. Therefore, reproducing the cost of reserves in a production cost model involves significant uncertainty, as it

\footnotetext{
${ }^{7}$ See https://www.caiso.com/Documents/DraftFinalProposal-FlexibleRampingProduct.pdf. The Flex Up product in this study holds back or brings online additional eligible generating capacity to meet a reserve requirement for the expected forecast error (uncertainty). Because this model is day-ahead only, we do not model the real-time usage of these reserves. The CAISO product, on the other hand, holds reserves in the 15-minute real-time unit commitment, releasing in the 5-minut real-time dispatch.
} 
was shown by Hummon et al. 2013. The flexibility reserve is less than the 600-MW regulation up reserve requirement for the three Flex Up scenarios. It is $15 \%-20 \%$ greater than the regulation up requirements for the three Flex Up High Wind scenarios. On average, the regulation up and regulation down requirements used in this model align with actual ERCOT procurements (Potomac Economics 2014).

Table 7. Production Simulation Model Reserve Requirements

\begin{tabular}{|c|c|c|}
\hline Reserve Type ${ }^{a, b, c}$ & Average Requirement (MW) & Scenario \\
\hline Flex Up 2012 & 423 & 2012 Flex Up \\
\hline Flex Up High Wind 2012 & 678 & 2012 Flex Up High Wind \\
\hline Flex Up 2013 & 468 & 2013 Flex Up \\
\hline Flex Up High Wind 2013 & 712 & 2013 Flex Up High Wind \\
\hline Flex Up 2014 & 486 & 2014 Flex Up \\
\hline Flex Up High Wind 2014 & 734 & 2014 Flex Up High Wind \\
\hline Spinning & 2,800 (constant) & All \\
\hline Non-Spinning & 1,500 (constant) & All \\
\hline Regulation Down & 600 (constant) & All \\
\hline Regulation Up & 600 (constant) & All \\
\hline
\end{tabular}

The Retire 4GW Coal scenario was intended to model the impacts of significant retirements due to cost-prohibitive upgrades and retrofits required to meet a variety of future regulations. We chose to retire $4 \mathrm{GW}$ based on ERCOT analyses of proposed and/or recent environmental regulations (ERCOT 2014 and 2015).

In this Retire 4GW Coal scenario, we retired coal units based on unit age, as represented in the Velocity Suite (Ventyx 2015) data. We retired generators in proportion to the capacity in different regions: approximately $2 / 3$ in the North zone and $1 / 3$ in the South zone. This led to retiring all units 38 years old and older in the North zone (representing 2,600 MW of capacity) and 36 years old or older in the South zone (representing 1,200 MW of capacity). These retirements represent $23 \%$ of the capacity of the existing coal fleet in the model. 


\section{Results}

We validated and compared a series of markup strategies to better understand the impact of market behaviors on production cost, revenue, and generation; analyzed sensitivity scenarios to better understand revenue sufficiency; and calculated reliability metrics to understand the closely-linked impact of our sensitivity scenarios on resource adequacy. We showed that markups impact prices by serving as a proxy for behavior, and we then used the most suitable markup scenario in each year as the basis for a set of sensitivity analyses. The sensitivity scenarios showed that an additional reserve requirement increases net revenues, whereas higher wind penetration levels decrease net revenues. Retiring a large fraction of the coal generator fleet increases net revenues significantly. The revenues earned by the entire generation fleet are the lowest in the No Markup scenario. This scenario can potentially overestimate the revenue sufficiency challenges faced by the generators. When we added a proxy for strategic behavior, as in our Benchmark scenarios, the total revenues increased, thus potentially underestimating the revenue sufficiency challenges.

\subsection{Model Validation}

Various inputs and outputs from the production simulation model were validated against historic ERCOT capacity, generation, and prices for 2012-2014. For each year, the markup scenario with the best fit - primarily based on energy prices — was selected as that year's Benchmark case, from which all subsequent sensitivity cases were developed. The ancillary service capacity prices were also compared against historic values from ERCOT (ERCOT 2012-2014b). We focused on the 2013 Benchmark scenario in many of the results presented here because this case had the best fit across most of the hours throughout the year.

Installed generation capacity and historical generation mix data were available from both ERCOT and EIA. After scaling natural gas and coal generator capacities (coal reduced by $20 \%$ and natural gas by $10 \%$ ) to approach ERCOT reported data, the total generator installed capacities and annual generation mix (see Figure 1) were compared to EIA data. The model aligned within $10 \%$ and $7 \%$, respectively, of reported values from the 2013 EIA Forms 860 and 923 (EIA 2013a, 2013b). Another view of the annual generation mix for the 2013 Benchmark scenario is shown in Figure 2. 

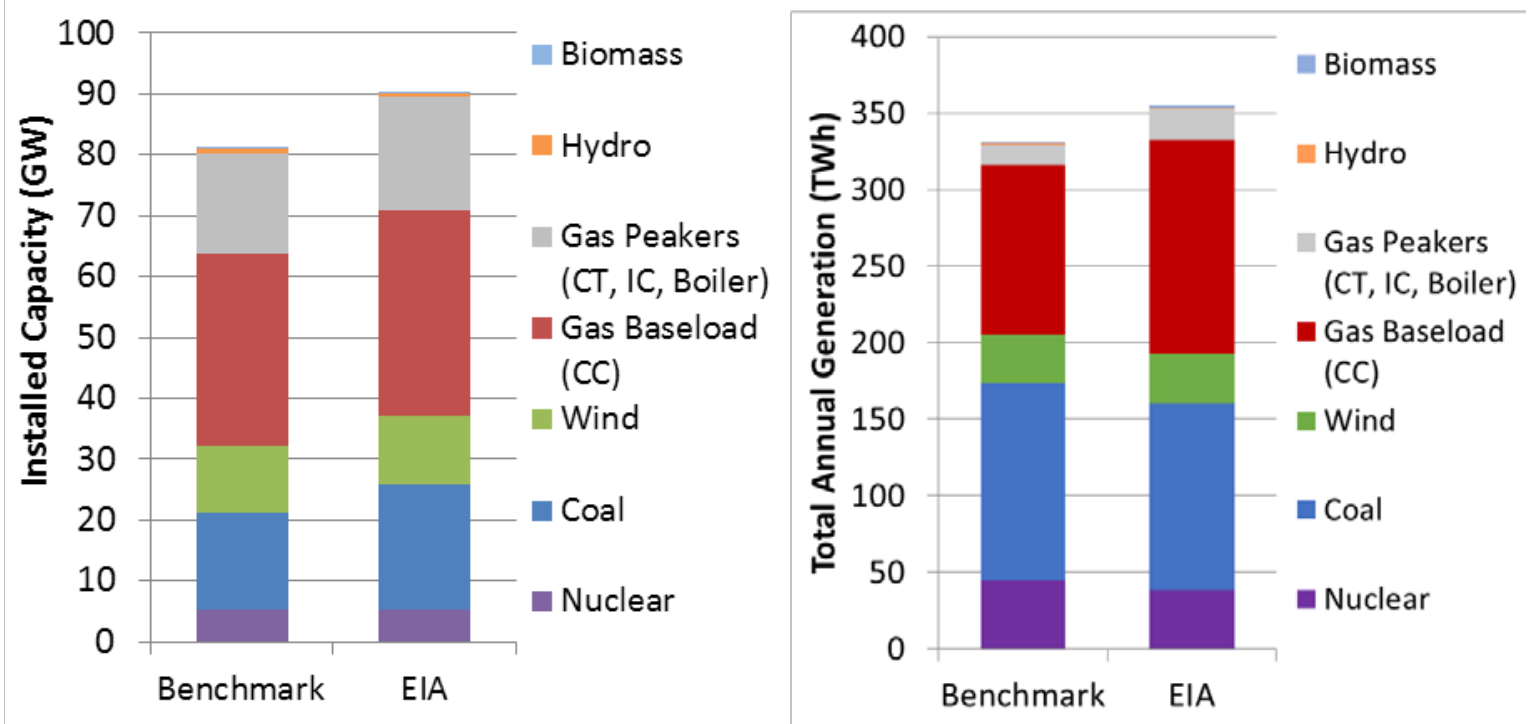

Figure 1. Production simulation model 2013 Benchmark scenario (0-40-80 markups) generator installed capacity (left) and annual generation mix (right) compared to historic reported EIA values

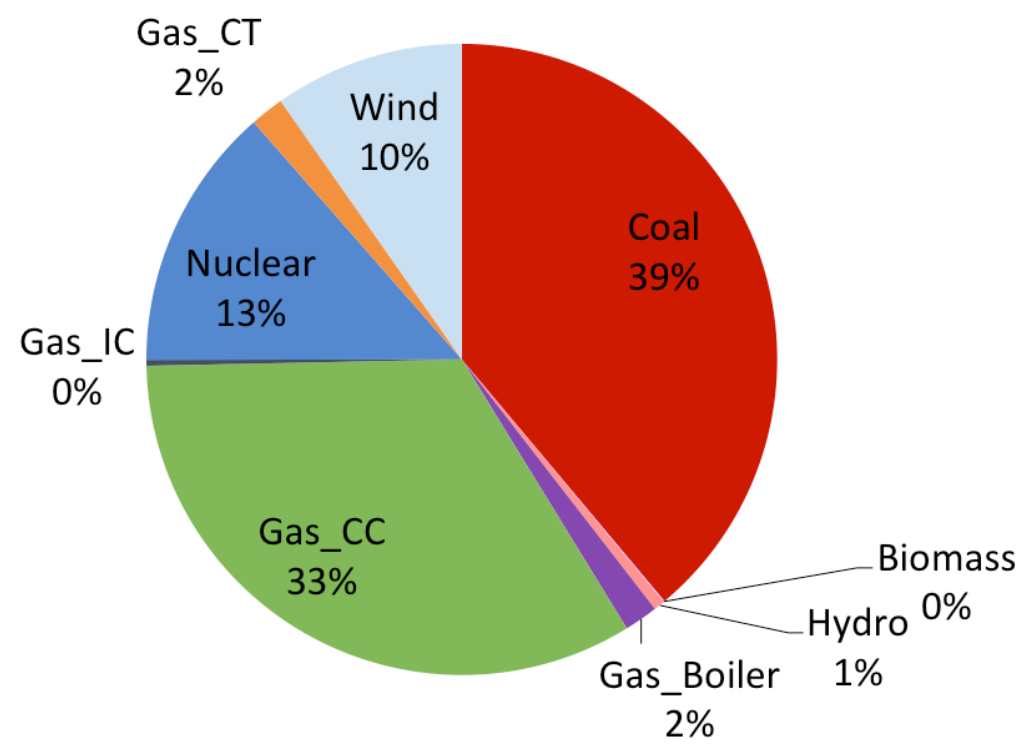

Figure 2. Annual generation mix for the 2013 Benchmark scenario

Energy price comparisons were made using the regional day-ahead price outputs from the production simulation model and historic day-ahead hourly ERCOT Settlement Point Prices (SPPs) ${ }^{8}$ from ERCOT (ERCOT 2012-2014). As shown by the 2013 price duration curves in Figure $3^{9}$ and the summary in Table 8 , the model captures the middle $80 \%$ of all hours well, but

\footnotetext{
${ }^{8}$ SPPs are averages of all resource node prices within each of the four trading hubs. ERCOT's publicly-available day-ahead SPP data set used in this analysis included values already averaged from the resource nodes to the trading hub-level. These prices are hourly for the day-ahead market. ERCOT provides an analogous data set for real-time prices.

${ }^{9}$ Duration curves for 2012 and 2014 are shown in Figure 22 and Figure 23, respectively, in Appendix A.
} 
it overestimates the upper tail and underestimates the lower tail. On a regional basis (see Figure 4), the West region captures the price depression in the lower tail from the large amount of wind generation.

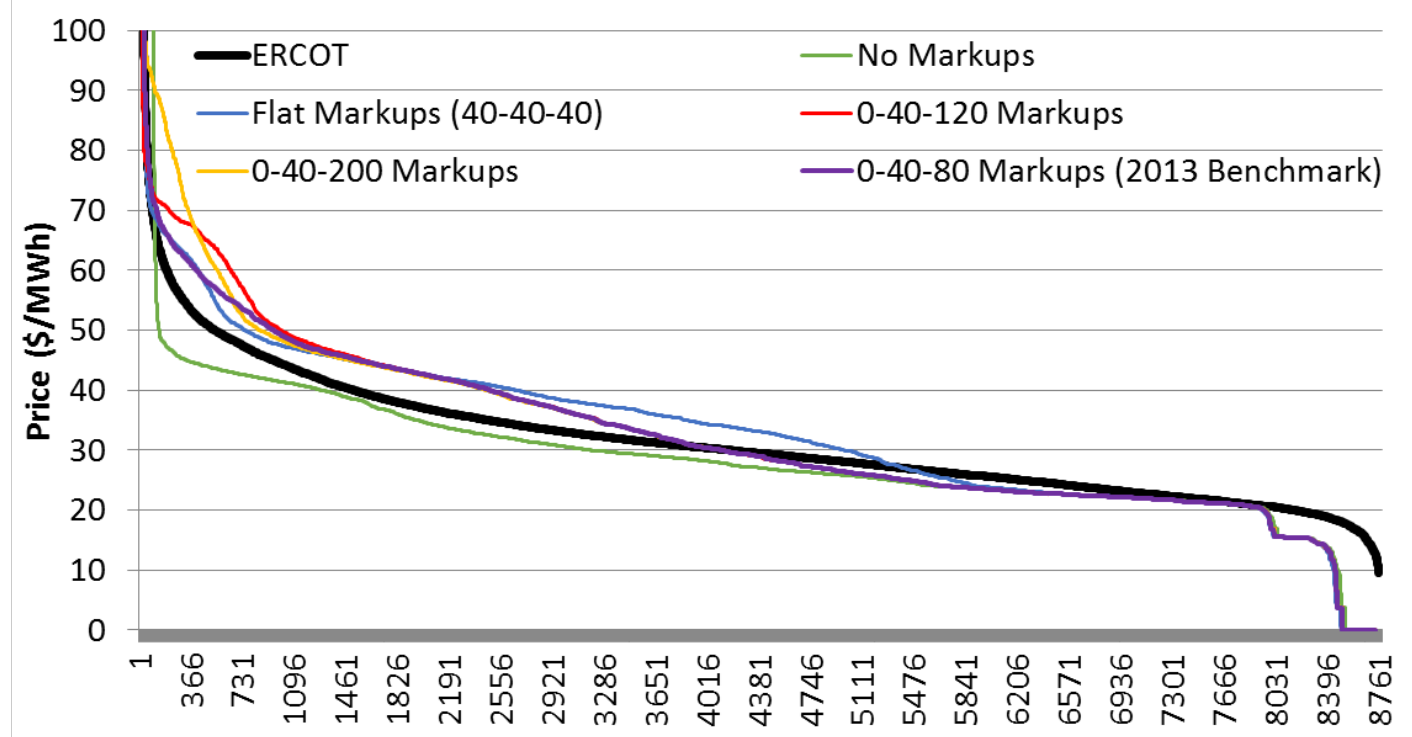

Figure 3. Day-ahead price duration curves averaged across all regions (magnified to show prices at or below \$100/MWh) for all 2013 markup scenarios and historic day-ahead SPPs from ERCOT 
Table 8. Energy Price Validation for the Middle $80 \%$ of All Hours for the 2012-2014 Benchmark Scenarios

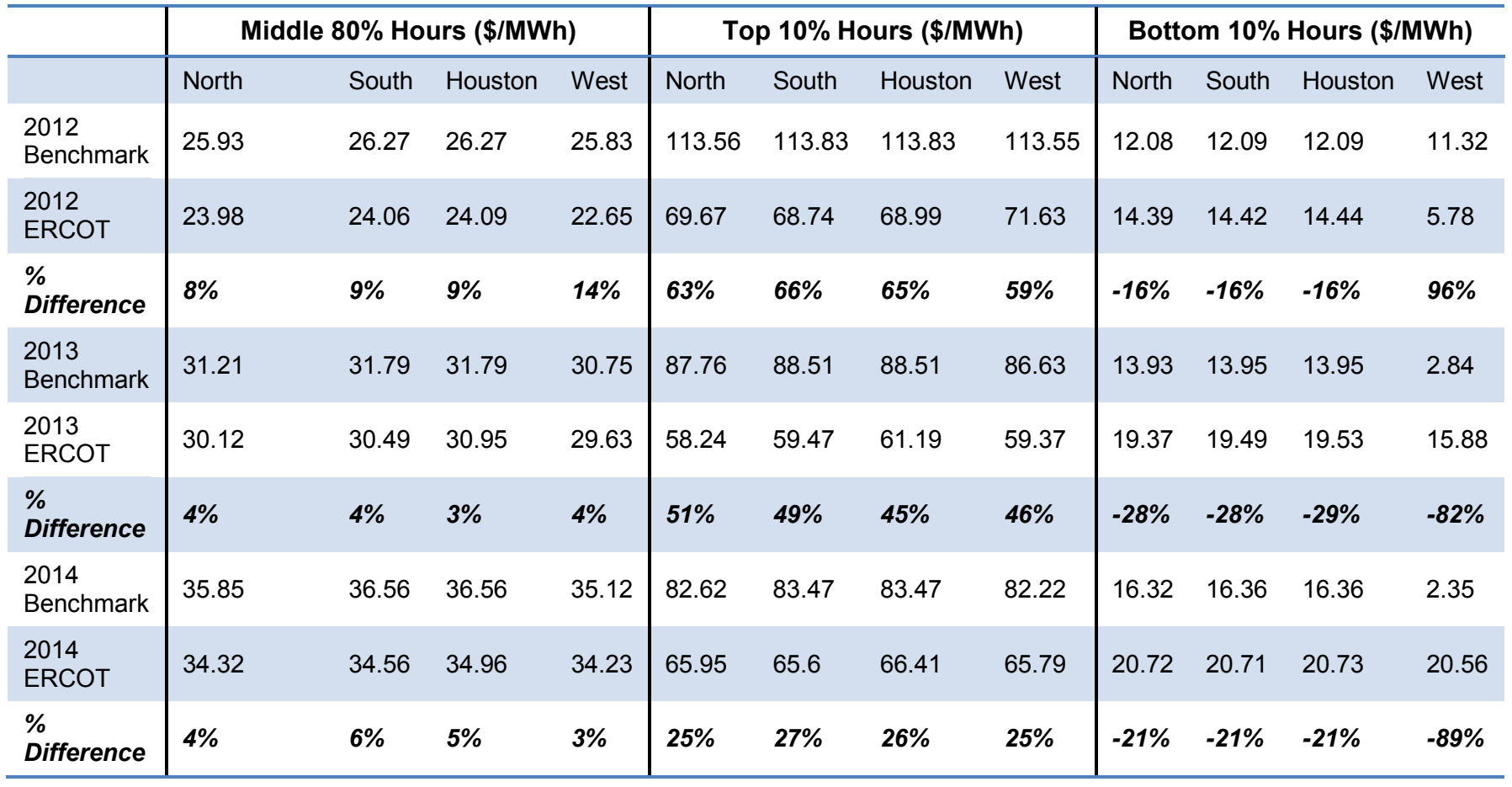

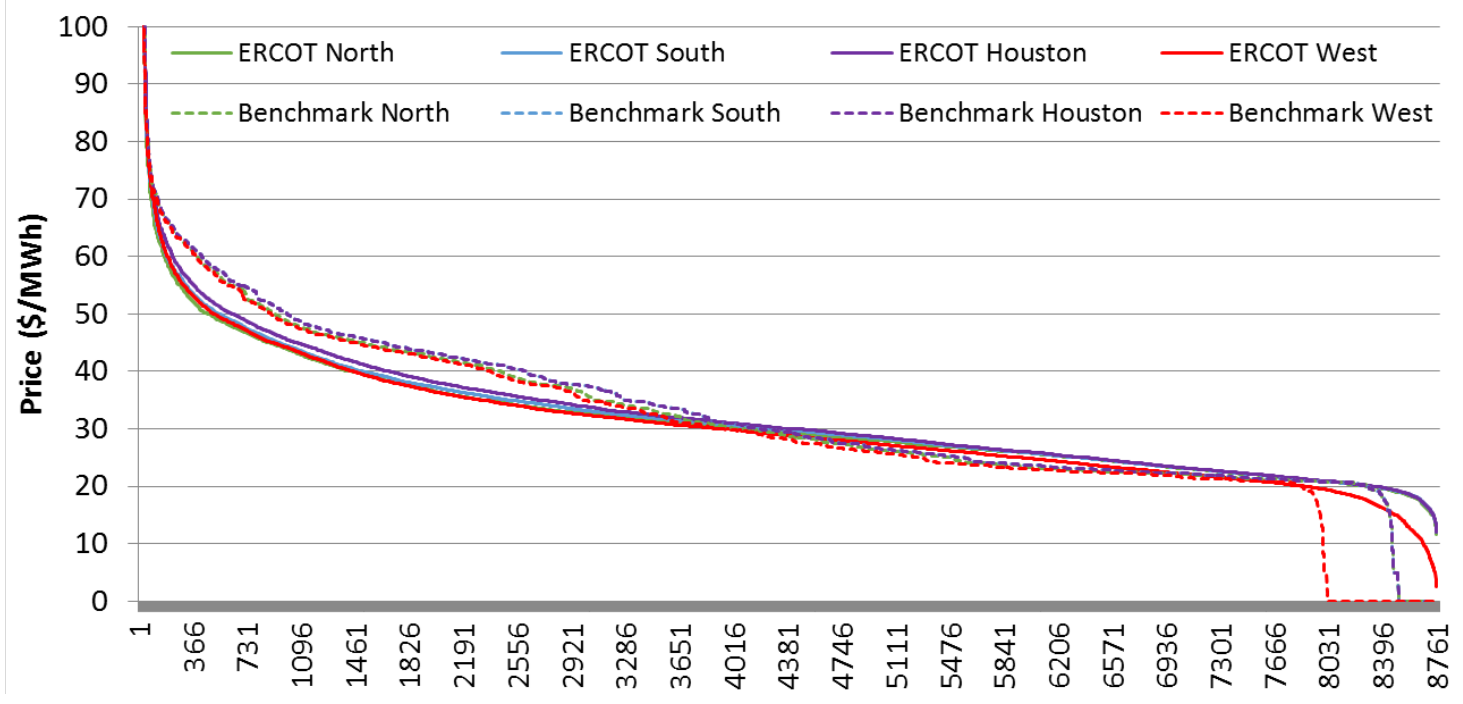

Figure 4. Regional day-ahead energy price duration curves (magnified to show prices at or below $\$ 100 / \mathrm{MWh}$ ) for the 2013 Benchmark scenario and historic day-ahead SPPs from ERCOT

Among the markup scenarios considered, we chose for the Benchmark the scenario that overall met or exceeded the historic SPP prices (and likely also revenues) so that any revenue sufficiency challenges identified in this analysis would be underestimated. The selected Benchmark scenarios (0-40-80 for 2012 and 2013, 0-40-200 for 2014) are indicated by the legend in the price duration curves shown below. As shown in Table 9, the No Markups scenario, which represents an "out-of-box" production cost simulation, underestimates prices 
(and therefore revenues), which would overestimate - or even artificially create - revenue sufficiency issues. Conversely, our Benchmark scenarios, which include graduated markups, overestimated the prices in the majority of all hours.

Table 9. Percent Increase in Day-Ahead Energy Prices from Historic ERCOT Data for the Middle $80 \%$ of All Hours

\begin{tabular}{|lcccc}
\hline & North & South & Houston & West \\
\hline 2012 Benchmark & $8 \%$ & $9 \%$ & $9 \%$ & $14 \%$ \\
\hline $\mathbf{2 0 1 2}$ No Markups & $-4 \%$ & $-3 \%$ & $-3 \%$ & $2 \%$ \\
\hline $\mathbf{2 0 1 3}$ Benchmark & $4 \%$ & $4 \%$ & $3 \%$ & $4 \%$ \\
\hline $\mathbf{2 0 1 3}$ No Markups & $-6 \%$ & $-6 \%$ & $-7 \%$ & $-6 \%$ \\
\hline $\mathbf{2 0 1 4}$ Benchmark & $4 \%$ & $6 \%$ & $5 \%$ & $3 \%$ \\
\hline $\mathbf{2 0 1 4}$ No Markups & $-6 \%$ & $-5 \%$ & $-6 \%$ & $-7 \%$ \\
\hline
\end{tabular}

On a daily and monthly basis, the model energy prices have profiles comparable to historic data, but the peaks are again overestimated, as shown in Figure 5 and Figure 6 for the 2013

Benchmark scenario (solid lines) and 2013 historic SPPs from ERCOT (ERCOT 2012-2014).

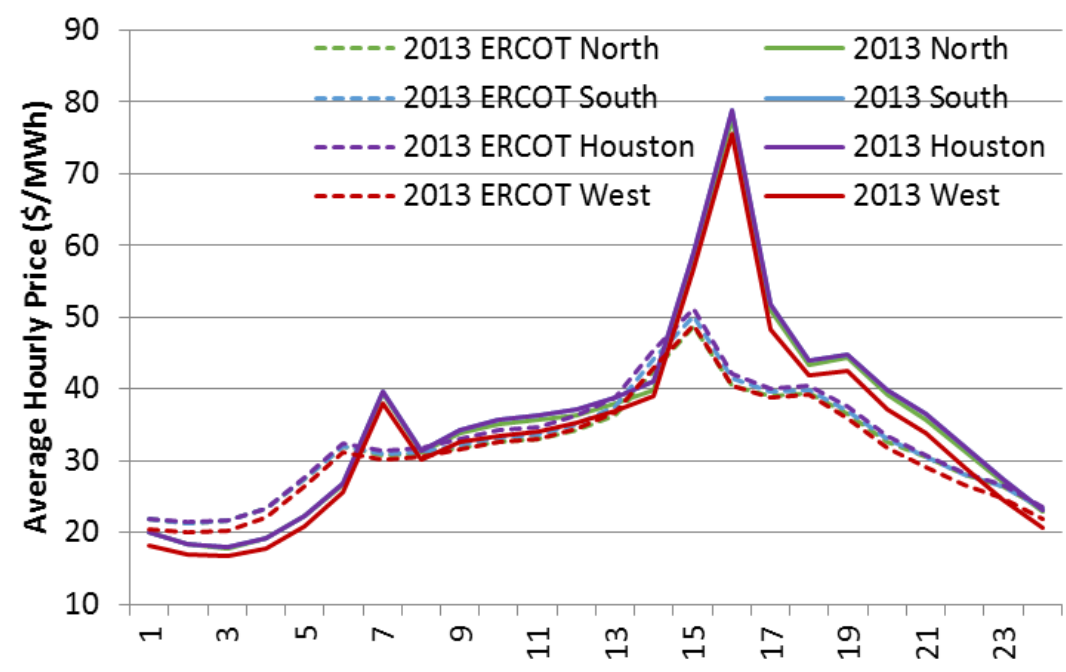

Figure 5. Regional average hourly day-ahead energy price by hour of day for the 2013 Benchmark scenario compared to the historic day-ahead SPPs from ERCOT 


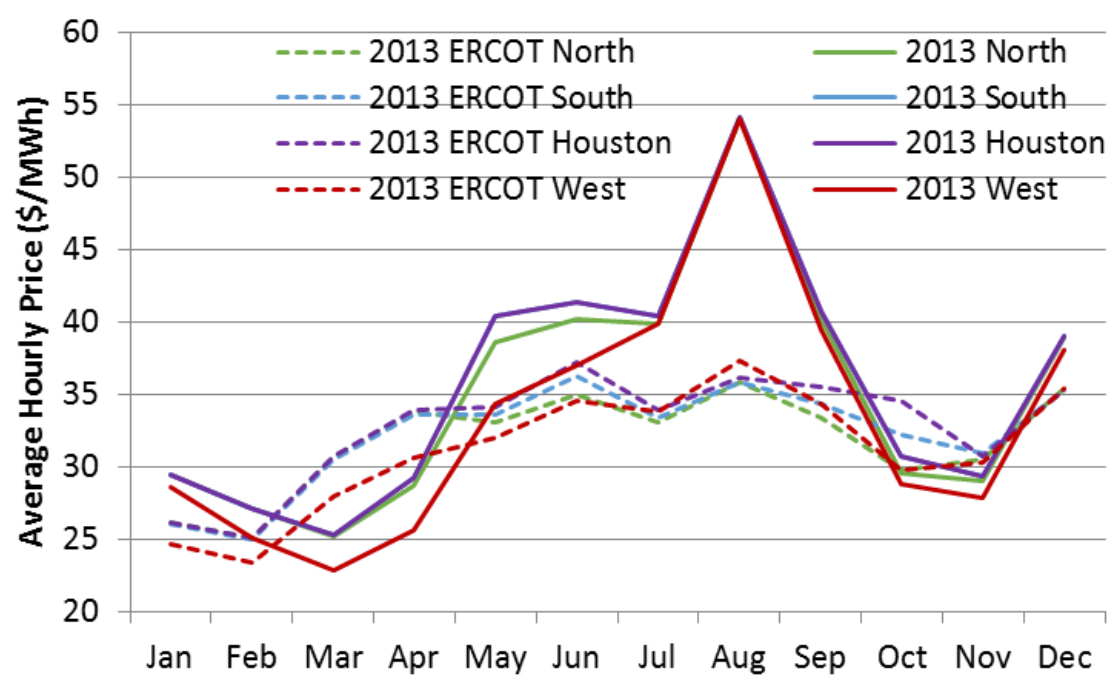

Figure 6. Regional average hourly day-ahead energy price by month for the 2013 Benchmark scenario compared to the historic day-ahead SPPs from ERCOT

On the whole, prices increase each year from 2012-2014 (Table 8), which is driven by the significant increase in natural gas fuel price, as shown in Table 10. Although wind does have large relative growth (see Table 6), the absolute production is still outweighed by load.

Table 10. Load, Wind, and Natural Gas Summary Inputs for the Benchmark Scenarios by Year

\begin{tabular}{lc}
\hline & $\begin{array}{l}\text { Average Natural } \\
\text { Gas Prices } \\
\text { (\$/MMBTU) }\end{array}$ \\
\hline $\mathbf{2 0 1 2}$ & \multicolumn{2}{c}{2.75} \\
\hline 2013 & \multicolumn{2}{c}{3.73} \\
\% Increase from $\mathbf{2 0 1 2}$ & $36 \%$ \\
\hline $\mathbf{2 0 1 4}$ & \multicolumn{2}{|c}{4.39} \\
\hline \% Increase from $\mathbf{2 0 1 3}$ & \multicolumn{1}{|c}{ 18\% } \\
\hline
\end{tabular}

Natural gas fuel prices are a key driver in the results presented here. Natural gas fuel prices were input to the PLEXOS model as monthly values (Table 2) that were based on historical natural gas prices for electricity generators in Texas, as implemented in Townsend (2013) and originally taken from the Energy Information Administration (EIA 2012). Natural gas fuel prices were much lower in 2012 relative to 2013 and 2014, which yielded noticeably different results for our 2012 markup scenarios from those observed in 2013 and 2014. For example, the low natural gas fuel prices made natural gas CC generators economically preferable to coal generators in $11 \%$ $16 \%$ of all hours in 2012. This was observed across the full set of 2012 markup scenarios, particularly in the lowest 2012 gas price months of November and December. Conversely, this natural gas $\mathrm{CC}$ versus coal marginal cost trade-off was only observed for a few hours among all 2013 and 2014 markup scenarios. 
Ancillary service prices were also compared with historic day-ahead market clearing prices from ERCOT (ERCOT 2012-2014b). The ancillary service products were spinning ("Spin”), nonspinning ("Non-Spin"), Regulation Up ("Reg Up"), and Regulation Down ("Reg Down"), as shown in Table 7. As shown in Figure 7 and Table 11, the PLEXOS model tended to underestimate non-spinning and spinning reserve prices and overestimate Regulation Down prices. Regulation Up prices more closely matched across all years, and regulation down prices had better alignment in 2014. However, reserves contribute a small fraction of the total system revenue and thus have only a small impact on the revenue sufficiency calculation.

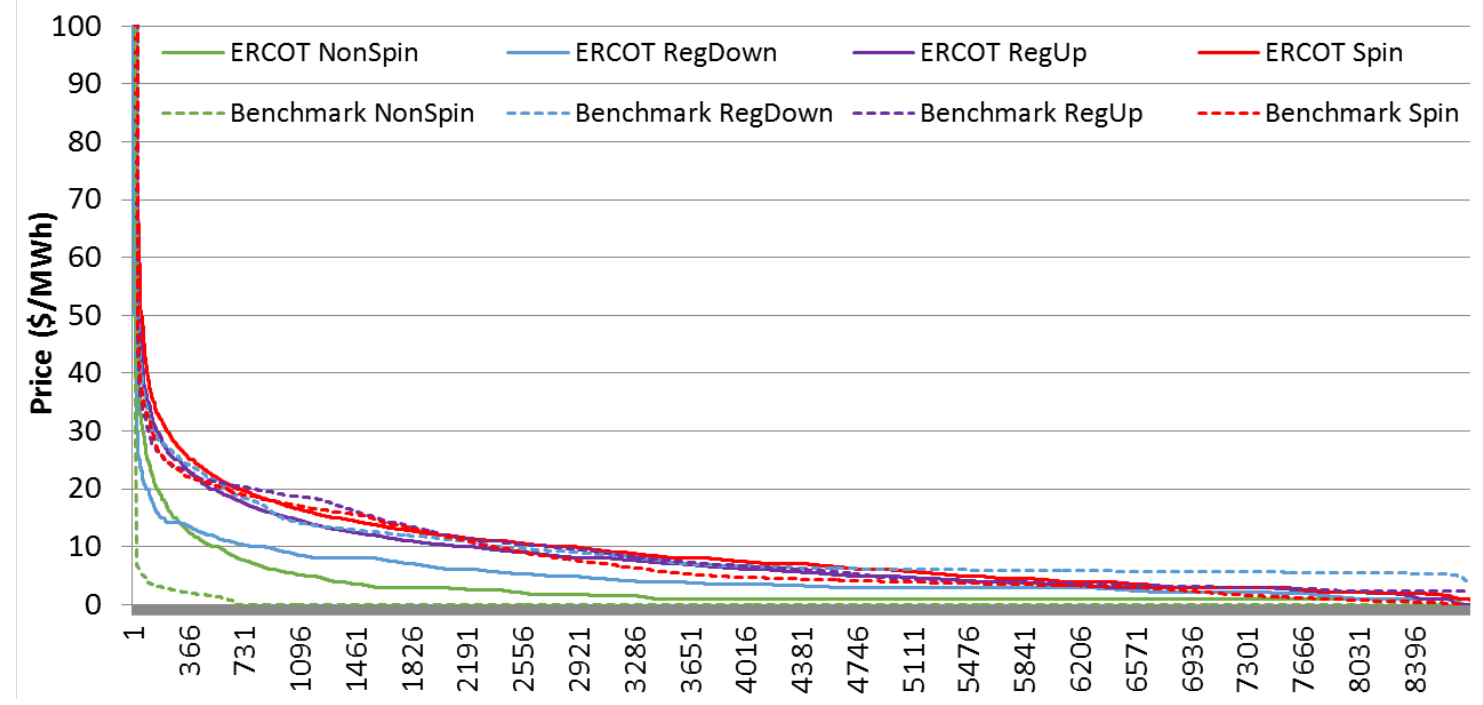

Figure 7 Ancillary service price duration curves averaged across all regions (magnified to show prices at or below $\$ 100 / \mathrm{MWh}$ ) for 2013 Benchmark scenario and historic day-ahead ancillary service prices from ERCOT 
Table 11. Average Ancillary Service Prices for the Middle $80 \%$, Top $10 \%$, and Bottom $10 \%$ of All Hours from the 2012-2014 Benchmark Scenarios and Historic Day-Ahead Ancillary Service Prices from ERCOT

\begin{tabular}{|c|c|c|c|c|c|c|c|c|c|c|c|c|}
\hline & \multicolumn{4}{|c|}{ Middle $80 \%$ Hours (\$/MWh) } & \multicolumn{4}{|c|}{ Top $10 \%$ Hours ( $\$ / M W h)$} & \multicolumn{4}{|c|}{ Bottom $10 \%$ Hours (\$/MWh) } \\
\hline & $\begin{array}{l}\text { Reg. } \\
\text { Down }\end{array}$ & $\begin{array}{l}\text { Reg. } \\
\text { Up }\end{array}$ & $\begin{array}{l}\text { Non- } \\
\text { Spin }\end{array}$ & Spin & $\begin{array}{l}\text { Reg. } \\
\text { Down }\end{array}$ & $\begin{array}{l}\text { Reg. } \\
\text { Up }\end{array}$ & $\begin{array}{l}\text { Non- } \\
\text { Spin }\end{array}$ & Spin & $\begin{array}{l}\text { Reg. } \\
\text { Down }\end{array}$ & $\begin{array}{l}\text { Reg. } \\
\text { Up }\end{array}$ & $\begin{array}{l}\text { Non- } \\
\text { Spin }\end{array}$ & Spin \\
\hline $\begin{array}{l}2012 \\
\text { Benchmark }\end{array}$ & 7.19 & 3.35 & 0.01 & 2.18 & 73.03 & 62.29 & 52.49 & 72.26 & 4.43 & 2.40 & 0.01 & 0.05 \\
\hline $\begin{array}{l}2012 \\
\text { ERCOT }\end{array}$ & 3.92 & 5.48 & 1.47 & 6.14 & 10.11 & 44.68 & 24.90 & 47.27 & 0.81 & 0.96 & 0.01 & 1.18 \\
\hline $\begin{array}{l}2013 \\
\text { Benchmark }\end{array}$ & 7.92 & 7.48 & 0.01 & 6.40 & 47.43 & 46.30 & 20.27 & 50.22 & 5.35 & 2.40 & 0.01 & 0.50 \\
\hline $\begin{array}{l}2013 \\
\text { ERCOT }\end{array}$ & 4.11 & 6.54 & 1.69 & 7.62 & 15.10 & 31.95 & 20.28 & 34.99 & 0.92 & 1.43 & 0.99 & 1.83 \\
\hline $\begin{array}{l}2014 \\
\text { Benchmark }\end{array}$ & 8.59 & 8.77 & 0.01 & 8.10 & 38.26 & 34.32 & 7.21 & 35.53 & 5.41 & 2.40 & 0.01 & 0.74 \\
\hline $\begin{array}{l}2014 \\
\text { ERCOT }\end{array}$ & 7.43 & 8.11 & 2.80 & 10.37 & 36.25 & 57.69 & 31.38 & 55.77 & 2.05 & 2.28 & 0.99 & 2.89 \\
\hline
\end{tabular}

\subsection{Impact of Market Behaviors on Production Costs, Revenues, and Generation}

A key assumption of this study is the use of markups to emulate strategic bidding behaviors of market participants as a proxy for addressing the importance of modeling realistic behaviors and how markets operate in production cost modeling. Production cost models are not sufficient to accurately match historic prices without some tuning (Gallo 2016a, 2016b). In this section, we highlight how the use of markups, as well as the shape of those markups, impacts production costs, revenues, and generation. Our reported production costs represent the operational costs experienced by the generators and do not include the bid markups or any uplift or make-whole payments. Although these results do not provide direct answers to the revenue sufficiency question, they do highlight the important impact of markups on revenue results from production cost modeling, which will inform the subsequent revenue sufficiency analysis. We directly address the revenue sufficiency issue in Section 3.3.

Our benchmarking process determined that graduated markups - instead of no markups or flat markups - yielded prices that meet and exceed historic values, so they potentially underestimate any revenue sufficiency issues. No markups resulted in prices below historic values. Graduated markups combined the potential for maximizing profit with risk-averse behavior. Such markups have been shown to serve as a proxy for behavior (Gallo 2016b) and to help estimate the ability of generation companies to exercise market power under high penetrations of wind (Gallo 2016a). 
One main impact of markups is higher system-wide production costs. ${ }^{10}$ With markups, the system is dispatched less optimally, resulting in lower overall generator efficiencies and, therefore, also higher overall generator costs. In other words, the least-cost system is the No Markups scenario because the system is optimizing the true production cost instead of a markedup cost. This reduction in efficiency is reflected in some generator heat rates, where a larger heat rate corresponds to lower efficiency. Most notably, the CC average heat rate increases from 8.03 to 8.14 MMBTU/MWh when markups are applied in the 2013 Benchmark scenario relative to the 2013 No Markups scenario. These CC units become less efficient with markups because they are dispatched down to lower generation levels more frequently; as we later show, CCs experience a lower generation per unit and are run at part-load more often with markups. CT units, however, become more efficient with markups, with a heat rate reduction from 13.91 to 13.59 MMBTU/MWh when markups are applied in the 2013 Benchmark scenario relative to the 2013 No Markups scenario. Since CC units constitute a significantly larger fraction of the overall generation mix (Figure 2), the $\mathrm{CC}$ heat rate elevation trend outweighs the counter effect from the $\mathrm{CT}$ units in the overall system generator efficiency results.

The larger overall production costs with markup scenarios (Benchmark and Flat Markups) relative to the No Markups scenarios is shown in the annual totals (i.e., \$M/yr) across all generator types in Table 12 and normalized by installed capacity (i.e., $\$ / \mathrm{kW}$-yr) for a key subset of generator types in Figure 8 for 2013. Figure 8 and Table 12 show the reported values as the differences among total production costs in the scenarios, with the percent differences also indicated. For example, the notation "Benchmark minus No Markups" is used to tag the difference in total production costs that have been realized in the Benchmark scenario when compared to the No Markups scenario. The notation used to describe the other two cases follows the same rationale. Since all nuclear units are must-run for all time steps, their production costs are the same regardless of the markup scheme, hence the zero difference values in Figure 8 . The generator-level production costs are driven not only by the heat rate and efficiency trends discussed above, but also by the total amount of generation. For example, since CC units generate less with markups, they have lower production costs in the Benchmark case relative to No Markups despite the corresponding reduction in efficiency. The opposite generation and production cost trend is seen with coal, gas boiler, and CT units.

Table 12. Difference in Total Production Costs among Select 2013 Markup Scenarios

\begin{tabular}{lcccccc}
\hline $\begin{array}{l}\text { Total Annual Production } \\
\text { Costs (\$M/yr) }\end{array}$ & $\mathbf{2 0 1 2}$ & $\begin{array}{l}\% \\
\text { Difference }\end{array}$ & $\mathbf{2 0 1 3}$ & $\begin{array}{l}\% \\
\text { Difference }\end{array}$ & $\mathbf{2 0 1 4}$ & $\begin{array}{l}\% \\
\text { Difference }\end{array}$ \\
\hline $\begin{array}{l}\text { Benchmark minus } \\
\text { No Markups }\end{array}$ & 65 & $1.0 \%$ & 63 & $0.8 \%$ & 124 & $1.5 \%$ \\
\hline $\begin{array}{l}\text { Flat Markups minus } \\
\text { No Markups }\end{array}$ & 55 & $0.8 \%$ & 47 & $0.6 \%$ & 59 & $0.7 \%$ \\
$\begin{array}{l}\text { Benchmark minus } \\
\text { Flat Markups }\end{array}$ & 11 & $0.2 \%$ & 16 & $0.2 \%$ & 64 & $0.8 \%$ \\
\hline
\end{tabular}

\footnotetext{
${ }^{10}$ Production costs are the total annual variable generation costs experienced by the generators. These costs include all variable operations and maintenance costs, fuel costs, and start-up and shutdown costs. The production costs reported here do not include the markups.
} 


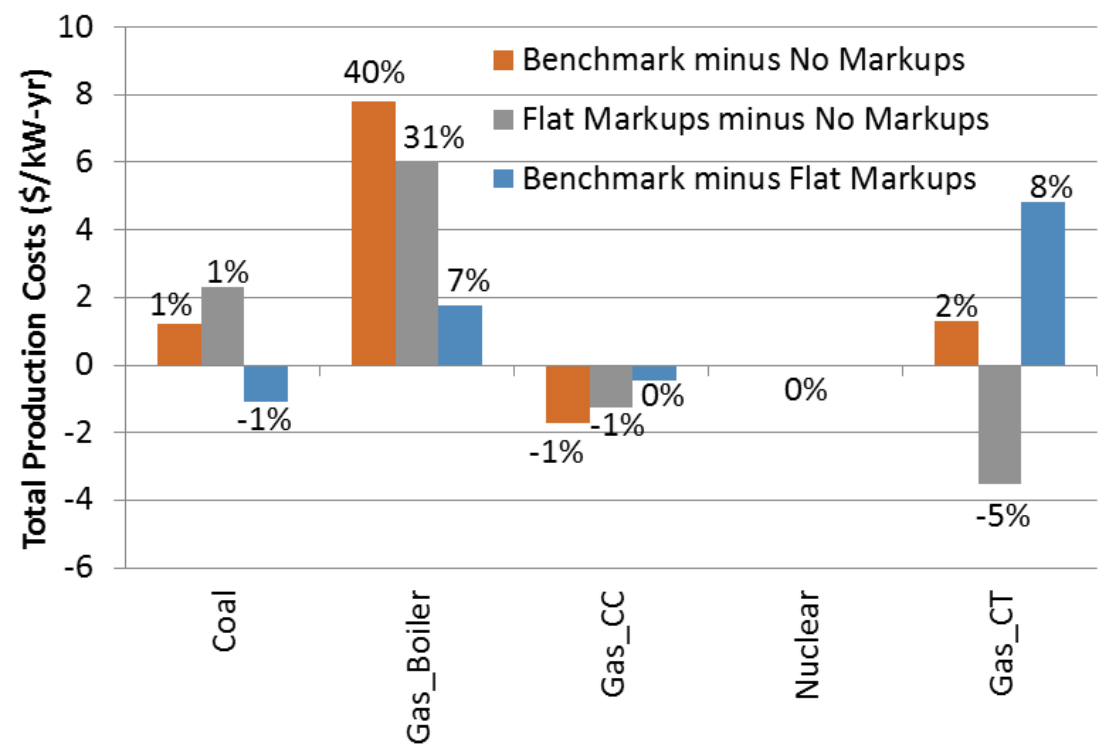

Figure 8. Normalized annual production cost differences among the 2013 Benchmark, No Markups, and Flat Markups scenarios

Markups also generally yield larger revenues (Figure 9), which follow from the associated increase in prices. However, this does not always compensate for the higher production costs, resulting in net revenues that may be lower or higher depending on the generator type (Figure 10). Among generator types, baseload generators (primarily coal and nuclear) benefit in any markup case because they are always running and benefit from the increased prices; this is reflected in their larger revenue and net revenue values. Natural gas CC and boiler generators, which run for large periods of the time but have greater flexibility than baseload units, see similar revenue and net revenue trends as the coal and nuclear baseload generators. Peaking plants, such as natural gas CT units, however, do not follow a clear trend. Instead, these peaking plants see progressively lower total revenues when moving from the No Markups to Flat Markups to graduate markups in the Benchmark scenario. Because of the large production costs for these units with graduated markups in the Benchmark scenario, the corresponding net revenues are negative. 


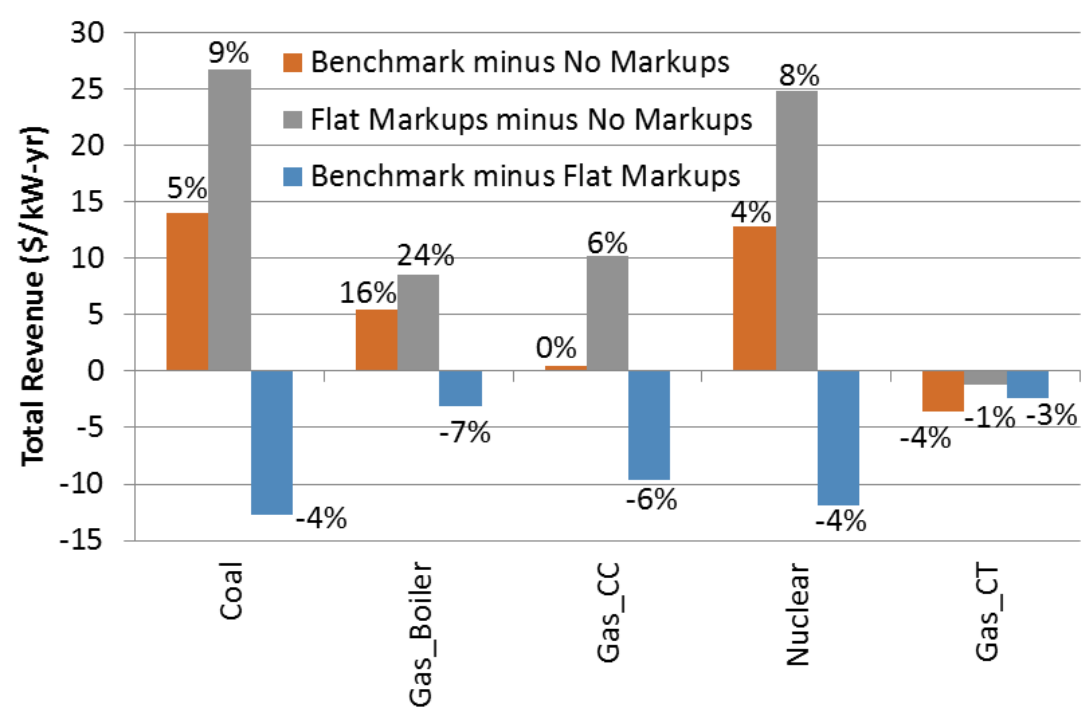

Figure 9. Normalized annual revenue differences among the 2013 Benchmark, No Markups, and Flat Markups scenarios

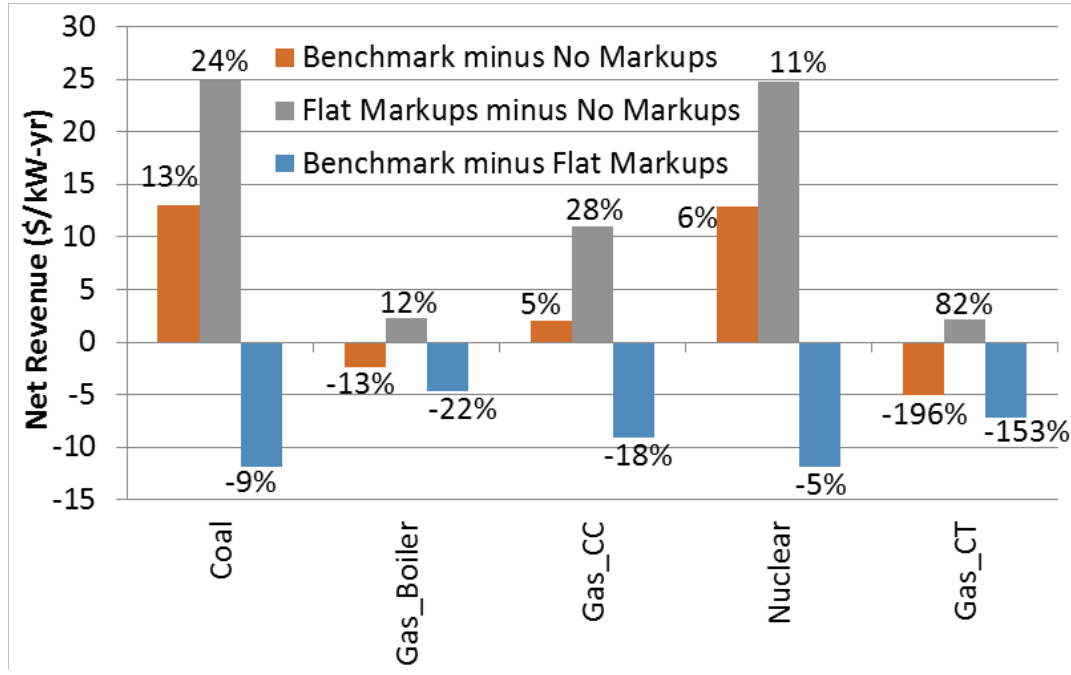

Figure 10. Normalized annual net revenue differences among the 2013 Benchmark, No Markups, and Flat Markups scenarios

In addition to the inclusion of markups in a production cost model, our study found that the shape of the markup curves matters. With graduated markups, it is more economical to run more units at part-load than to pay the extra markup (highest bin of graduated markups), resulting in more units online. This is reflected in the larger number of hours of operation (Figure 11), and it is especially noticeable with natural gas CC generators, which also have less total generation (Figure 12) and, consequently, less relative generation per unit.

The markup shape also impacts the market clearing process. In the Flat Markups scenario, where the generator bid offers are $40 \%$ larger than their true production costs in all three heat rate bins, generators benefit because the model cannot avoid paying markups. Conversely, generators benefit less with graduated markups in the Benchmark scenario because the model can avoid 
paying markups through the lowest bin option ( $0 \%$ markup). This advantage of the flat markups versus the graduated markups is reflected in the larger net revenues for the Flat Markups scenario relative to the Benchmark scenario, as shown in Figure 10. However, graduated markups are still used by some generators as a hedging mechanism; the multistep markup gives the generators the opportunity to diversify their bids across zero-, mid-, and high-markup options.

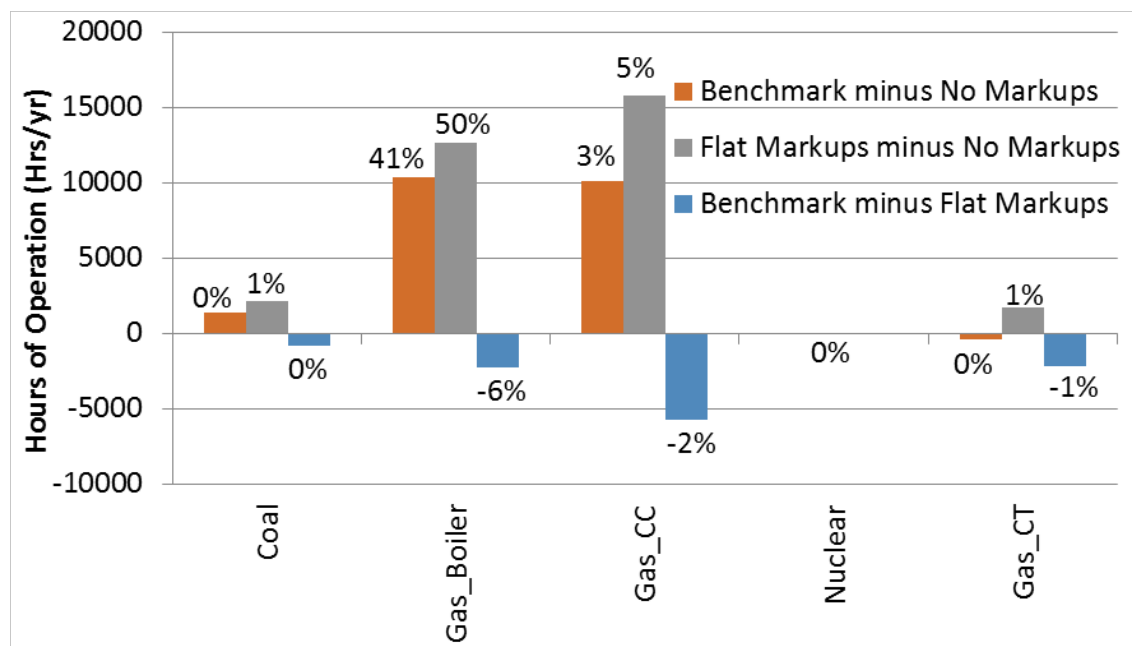

Figure 11. Total annual hours of operation differences among the 2013 Benchmark, No Markups, and Flat Markups scenarios

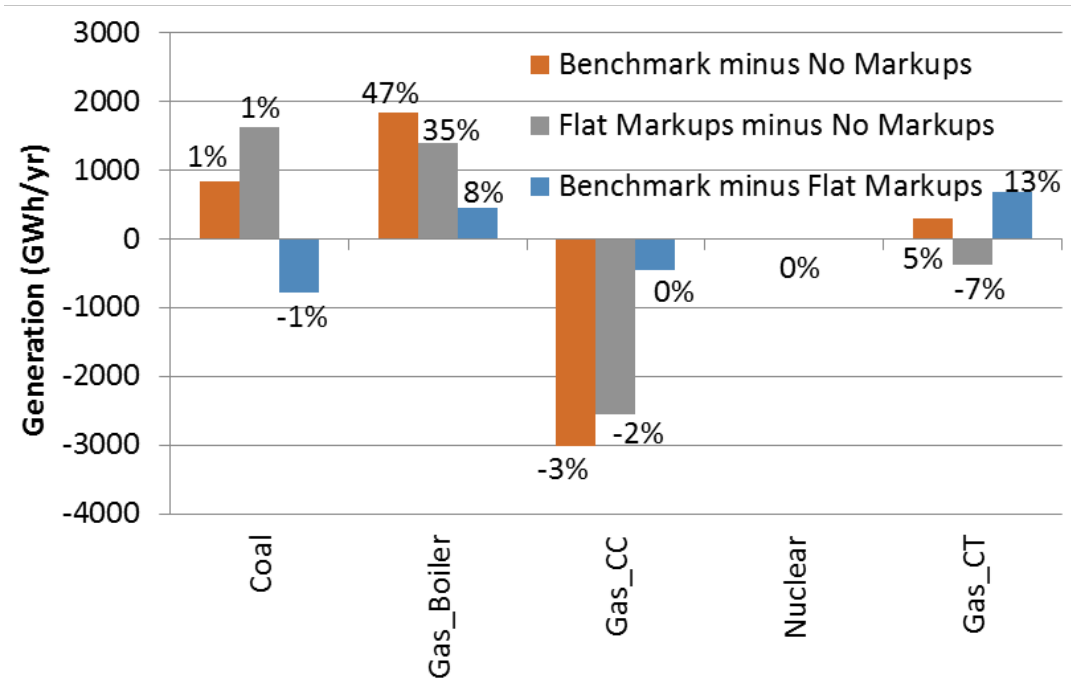

Figure 12. Total annual generation differences among the 2013 Benchmark, No Markups, and Flat Markups scenarios

\subsection{Sensitivity Analysis to Assess Revenue Sufficiency Challenges}

The previous sections described the model validation process, the resulting Benchmark scenario that was selected from an assortment of markup options, and the impact of markups on various model outputs. We now turn to the main objective of this work-revenue sufficiency challenges - through a set of sensitivity scenarios that use the Benchmark scenarios as their 
basis. As summarized in Table 4, four sensitivity scenarios were analyzed in addition to each year's selected Benchmark case:

- High Wind with approximately double the total wind penetration level as the base case (see Table 6)

- Flex Up with an additional flexible reserve requirement as described in Section 2

- Flex Up High Wind with an additional flexible reserve requirement and high wind

- Retire $4 \mathrm{GW}$ of Coal distributed across the North ( $2 / 3$ of retirements) and South $(\sim 1 / 3$ of retirements).

These scenarios explore the impact of possible future systems with high wind, additional reserve services, and generation retirements on revenue sufficiency. This section focuses primarily on revenue sufficiency, with a brief mention of resource adequacy implications in Section 3.4.

As a starting point, the absolute generation, revenues, production costs, hours of operation, and net revenue values for the Benchmark scenarios for each year are summarized in Table 13. Every metric except for net revenues increases from one year to the next, which reflects the complexity of the relationships among these components. In addition, daily and monthly net revenue (normalized to installed capacity) patterns roughly follow the same shape as prices, as expected, which are shown in Figure 13 and Figure 14 for the 2013 Benchmark scenario.

Table 13. Price, Revenue, and Operation Summary for the Benchmark Scenarios

\begin{tabular}{llll}
\hline & $\mathbf{2 0 1 2}$ & $\mathbf{2 0 1 3}$ & $\mathbf{2 0 1 4}$ \\
\hline Average Price (\$/MWh) & 33.4 & 35.0 & 38.4 \\
\hline Total Generation (TWh/yr) & 323 & 331 & 339 \\
\hline Total Revenue (\$B/yr) & 13.29 & 13.33 & 14.54 \\
$\begin{array}{l}\text { Total Production Costs } \\
\text { (\$B/yr) }\end{array}$ & 6.69 & 7.70 & 8.52 \\
\hline \begin{tabular}{l} 
Net Revenue (\$B/yr) \\
\hline
\end{tabular} & 6.56 & 5.59 & 6.02 \\
\hline
\end{tabular}




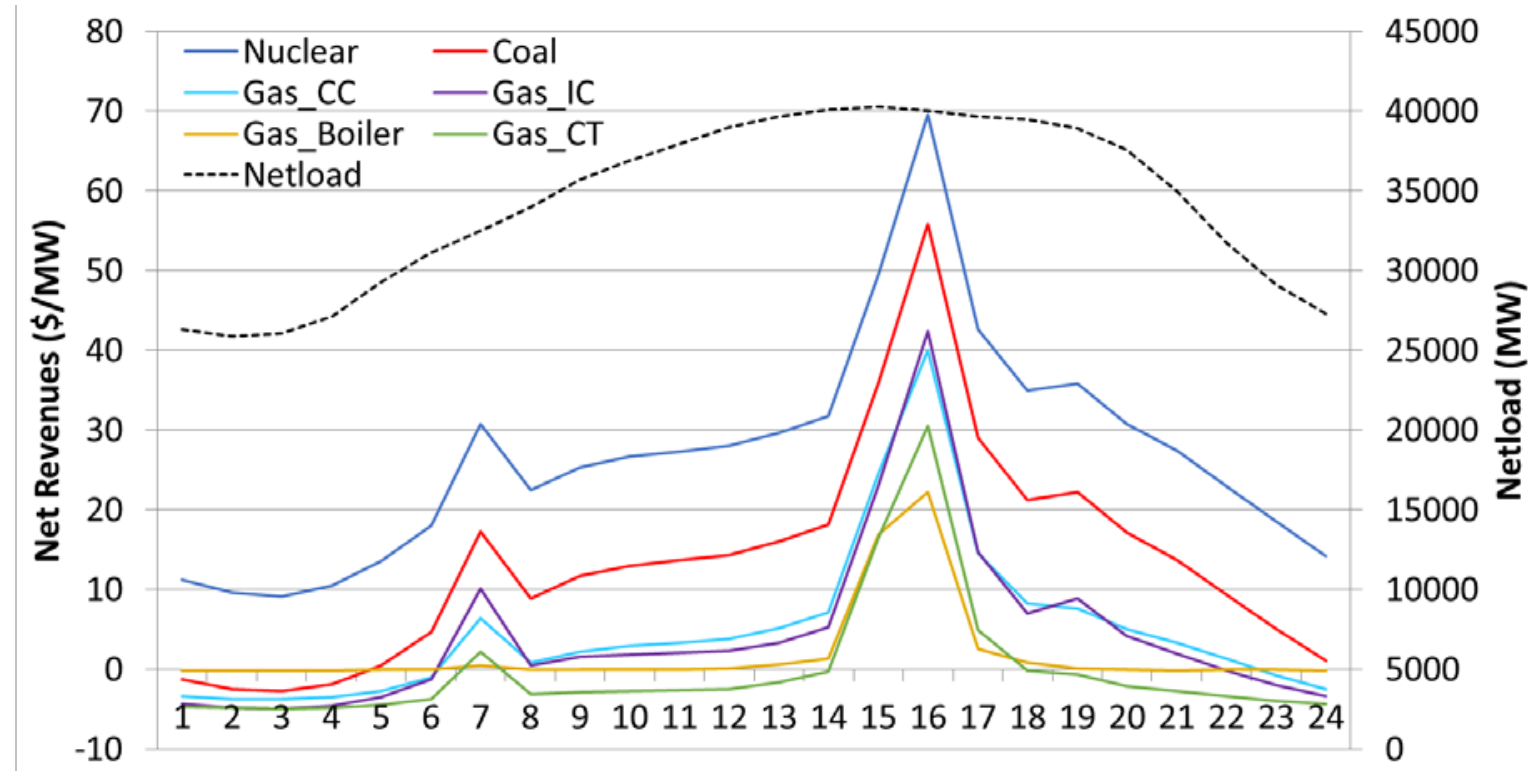

Figure 13. Net revenue averaged across each daily hour bin for the 2013 Benchmark scenario

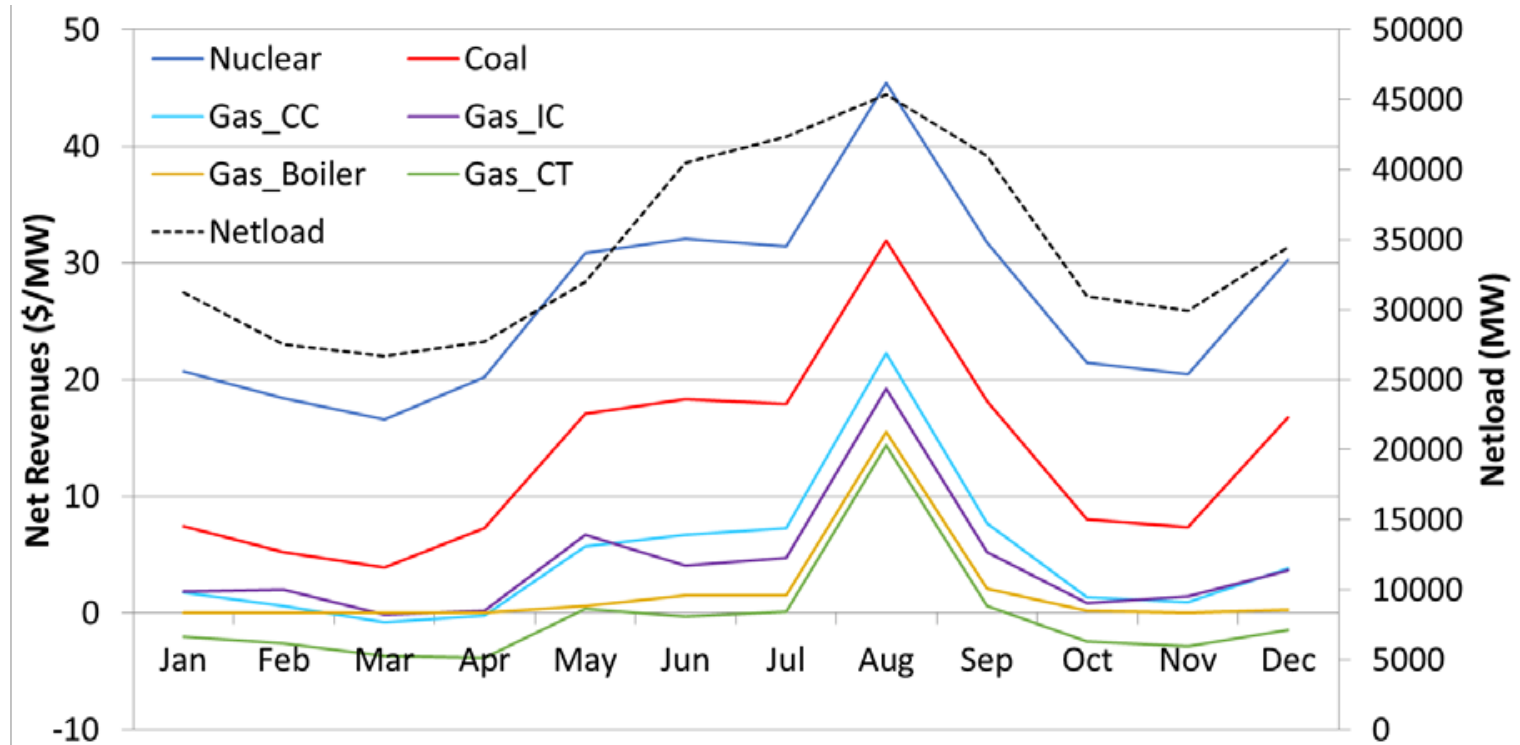

Figure 14. Net revenue averaged across all hours within each month for the 2013 Benchmark scenario

In all scenarios, negative net revenues were observed for some generators due to must-run constraints, indicating that these units were not earning enough revenue to cover their variable costs. This must-run constraint was applied a priori to selected units and required those individual generators to be committed in any hour that they were available. ${ }^{11}$ This primarily

\footnotetext{
${ }^{11}$ These must-run units "represent the private-use networks in ERCOT, which typically represent a large industrial customer with both generators and loads within the customer's site. These were assumed to be cogeneration facilities for industrial processes, and therefore were always assumed to be committed, but were not assumed to
} 
impacted CC and CT gas generators, where roughly $22 \%$ of the CC fleet and $25 \%$ of the CT fleet on a capacity basis were must-run. In the 2013 Benchmark scenario, these must-run CC generators comprised approximately $34 \%$ of all total annual generation from all CC units, and the must-run CT generators comprised approximately $72 \%$ of the total annual generation for all CT units. This contribution from must-run units is about $13 \%$ of the total generation mix (Figure $2)$, and a significant portion $(\sim 1 / 3)$ of the $\mathrm{CC}$ gas units.

A key objective of this study is to evaluate the revenue sufficiency implications of various market structures. Key metrics for this assessment include net revenues and peaker net margins (PNM), the latter of which is a standard metric used in the ERCOT State of the Market reports. Net revenues are the total revenues from all market sessions (energy and reserves in this study) minus the short-term production costs, and they represent the revenue available to meet fixed and capital costs, including a return on investment. When net revenue is negative, the generators are not able to earn enough revenue to cover their variable costs, indicating that a revenue sufficiency problem definitely exists. If net revenue is positive but is less than the annualized investment cost for a new generator, then the system does not provide the opportunity to earn sufficient revenue to justify investments in new capacity, and this also implies that existing generators are not earning enough revenue to cover their fixed costs.

Two versions of the net revenue metric are used in practice: one that includes generator start-up and shutdown costs, and one that does not. We found trivial differences between these versions in our results, as shown in Figure 15. Therefore, to err on the side of overestimating net revenues, only the version that includes start-up and shutdown costs was used in all subsequent results presented here. We focus on five key thermal and nuclear technologies for the revenue sufficiency results presented here: coal, gas boiler, gas CC, gas CT, and nuclear.

Revenue sufficiency challenges were implied for nearly all of the scenarios evaluated in this study using a simplified model of an ERCOT-like system. Figure 15 shows that the net revenues for the Benchmark scenarios (bars) aligned reasonably well with those reported in the ERCOT State of the Market reports (Potomac Economics 2013, 2014 and 2015). Numeric values from Figure 15 are provided in Table 15 in the Appendix. The dots represent the current annualized investment costs for new generator units as reported in NREL's presentation on the ATB ${ }^{12}$ (Blair et al. 2015). When these dots are larger than the achieved net revenues, as is the case for all generator types shown in Figure 15, then revenues were not sufficient to signal investments in new generation capacity. This could also reflect revenue sufficiency challenges for existing generators, depending on their sunk costs. If revenues are not sufficient to invest in new units when more capacity is needed to reliably meet load, then this can also lead to resource adequacy

\footnotetext{
always operate at full capacity. They were assumed to operate between their minimum and maximum generation levels as determined by the PLEXOS based on their variable costs" (Townsend 2013).

${ }^{12}$ Capital expenditure (CAPEX) values were used, which represent the total expenditures per kW plant capacity required to achieve commercial operation in a given year. For the technologies shown, the corresponding CAPEX values from the ATB database were assumed to be as follows: "Coal-new" for Coal; "Dedicated biomass plant" for Biomass; "Non-powered dam" supply curve Bin 1 (largest resource bin) for Hydro; "Gas-CC” for Gas_CC, Gas_IC, and Gas_Boiler; "Advanced nuclear" for Nuclear; "Gas-CT" for Gas_CT; and "Onshore wind" supply curve Bin 3 (largest resource bin) Wind. CAPEX values were annualized assuming a real capital recovery factor of $8.89 \%$.
} 
issues. Recall also that because the simulated market prices in these Benchmark scenarios are higher than historic prices, the revenue sufficiency challenges identified here are underestimated.

Revenue sufficiency challenges are also implied with PNM results, which is a key metric used in the State of the Market reports and indicates the net revenue required to satisfy the annual fixed costs (including capital carrying costs) of a new gas turbine unit. Figure 16 shows a monthly cumulative plot of PNM values for each of the Benchmark scenarios. These PNM values were calculated based on ERCOT's standard PNM method, ${ }^{13}$ except day-ahead hub prices were used instead of real-time energy prices, and monthly gas input fuel prices values were used instead of the Houston Ship Channel gas price (Potomac Economics 2013). For ERCOT, the annual fixed cost of a new gas turbine unit ranges from $\$ 80,000$ to $\$ 105,000$ per MW-year (Potomac Economics 2013); a value of $\$ 80,000 / \mathrm{MW}$-year is shown in Figure 16. As reported in the 2014 State of the Market Report, ERCOT's 2014 and subsequent year PNM threshold is three times the cost of new entry or CONE (Potomac Economics 2014). In this study, the 2012 and 2013 PNM results are nearly double those reported in the State of the Market reports, but 2014 aligns well with the 2014 reported values (Potomac Economics 2014). Except for the upper tail in 2012, the PNM did not even come close to reaching the minimum level needed to invest in a new gas turbine unit, reflecting revenue sufficiency challenges. The 2012 results may be skewed by the significantly lower natural gas fuel prices, as discussed above.

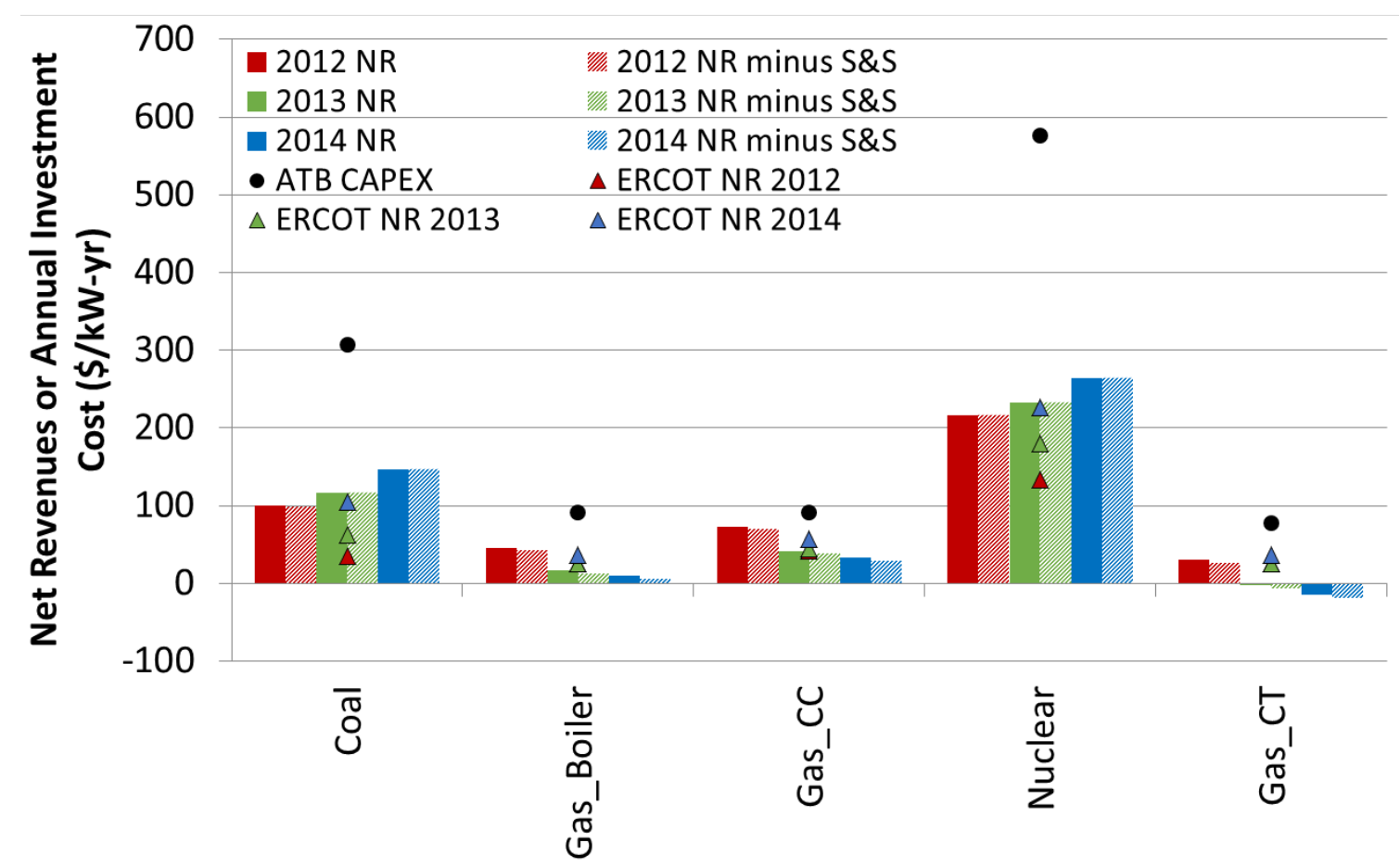

Figure 15. Benchmark scenarios net revenues with and without start-up and shutdown costs (S\&S) and compared to annualized investment costs from NREL's ATB and ERCOT's State of the Market reports (ATB value in 2013\$)

\footnotetext{
${ }^{13}$ Public Utility Commission of Texas Subst R $§ 25.505$ (g) and further explained in the ERCOT Business Practice System-Wide Offer Cap and Scarcity Pricing Mechanism Methodology
} 


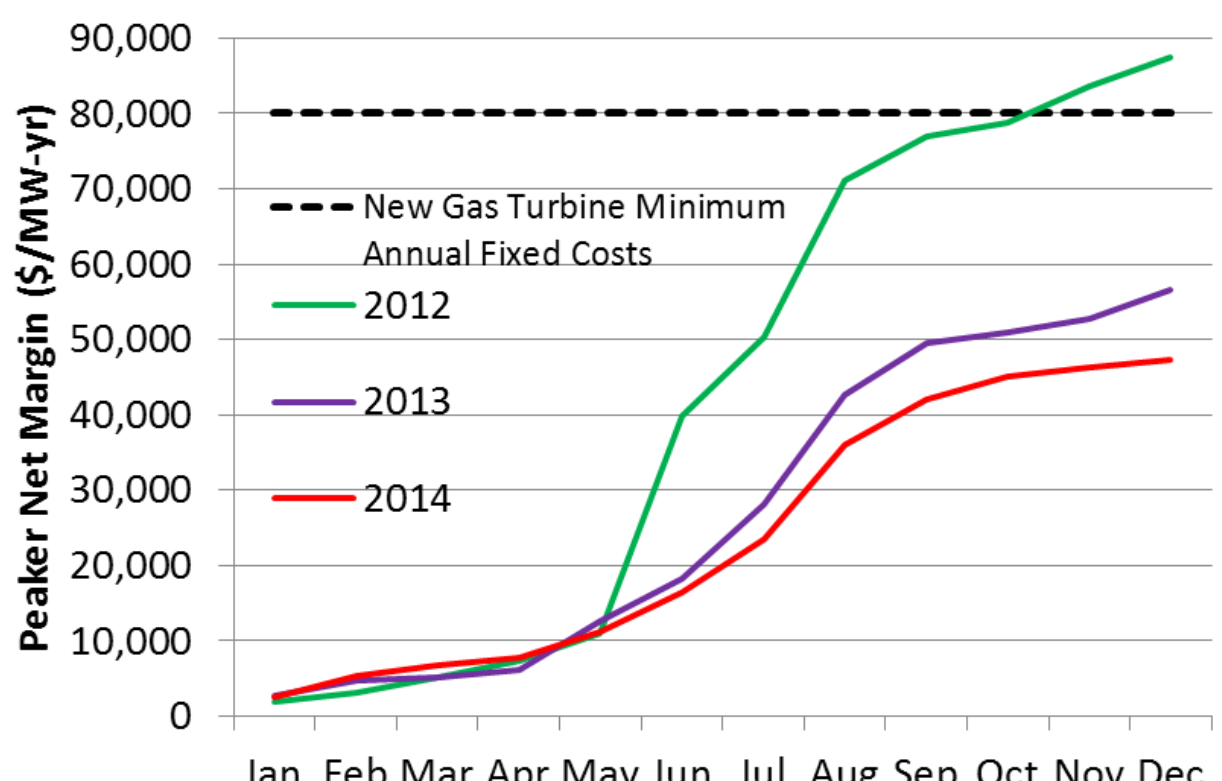

Figure 16. PNM for the 2012-2014 Benchmark scenarios

Results from the sensitivity scenarios reveal similar net revenue trends across all three years; the 2013 results normalized by installed capacity (i.e., \$/kW-yr) are shown in Figure 17 to Figure 20. Higher penetration of wind generation in the High Wind scenario depressed prices (Figure 17) and led to lower net revenues (Figure 18 and Figure 19).

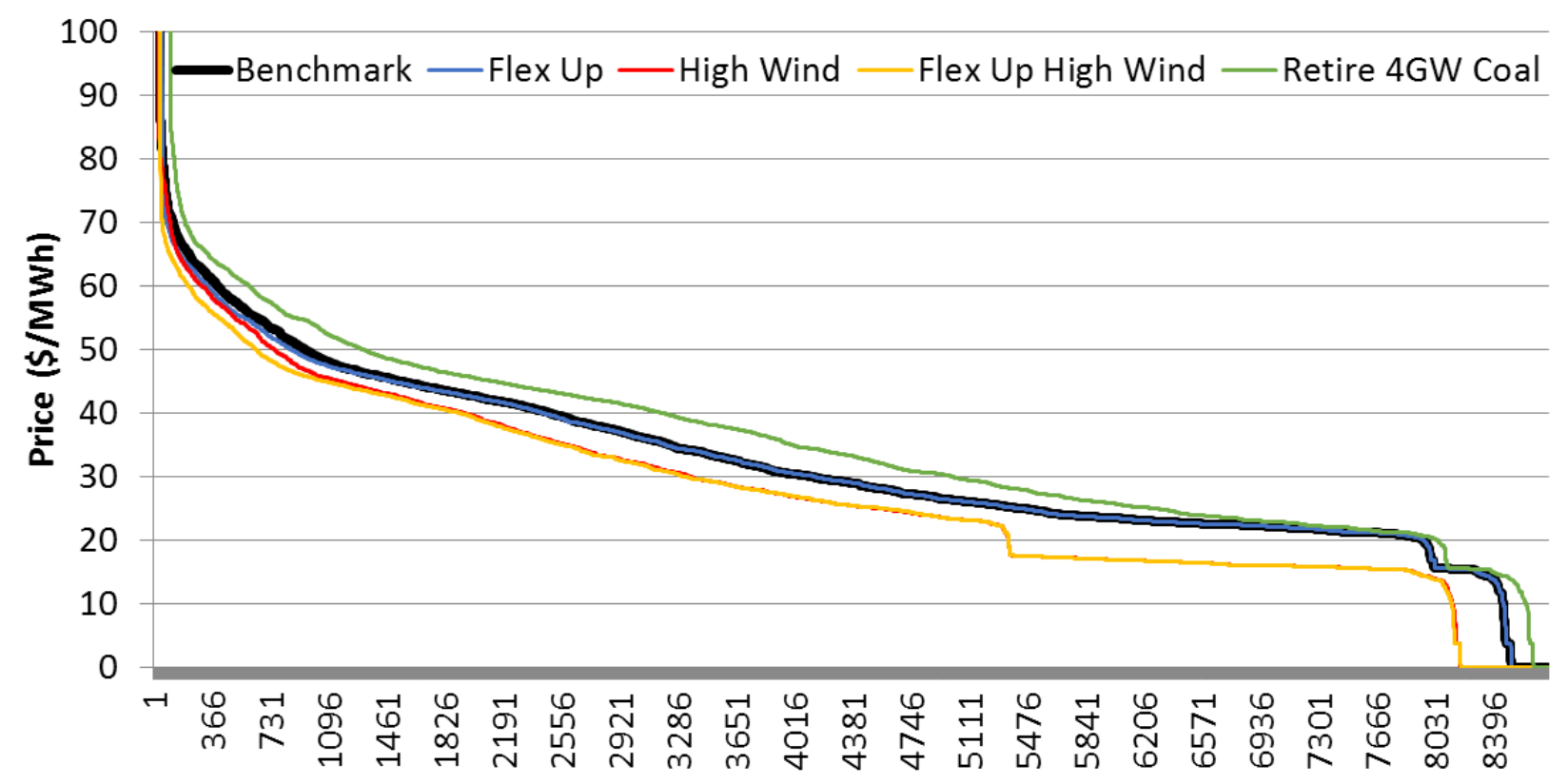

Figure 17. Price duration curves averaged across all regions (magnified to show prices at or below $\$ 100 / \mathrm{MWh}$ ) for the 2013 Benchmark and all sensitivity scenarios 
The similarity between the High Wind and Flex Up High Wind scenarios suggests that the results are influenced more strongly by high wind than by the addition of a flexibility reserve. Most notably, however, revenue sufficiency remained an issue in nearly all scenarios, as reflected by net revenue values (bars) that were lower than the corresponding annualized investment costs (dots) in Figure 18. The only exception was when large amounts of coal were retired in the Retire 4GW Coal scenario, wherein investment in new generators was supported for all types but nuclear, which has an annualized investment cost that is slightly larger than the achieved net revenue.

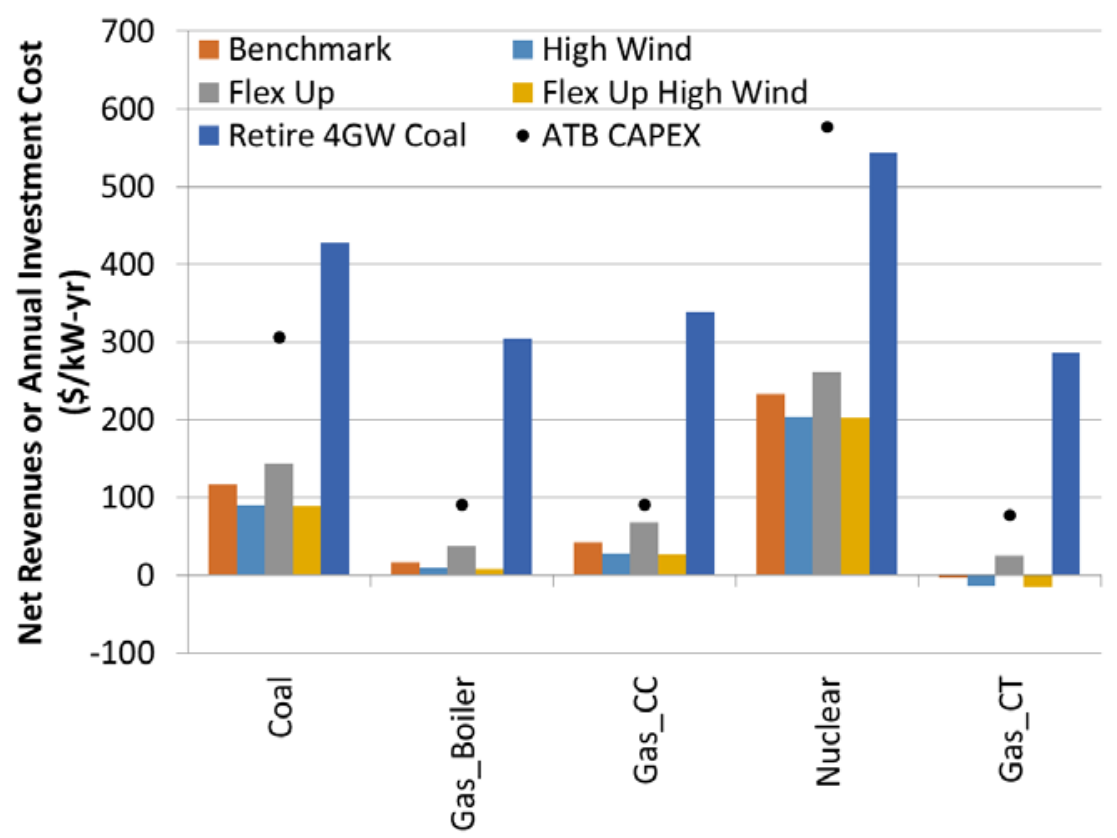

Figure 18. Net revenues for the 2013 Benchmark and sensitivity scenarios and ATB annualized investment costs

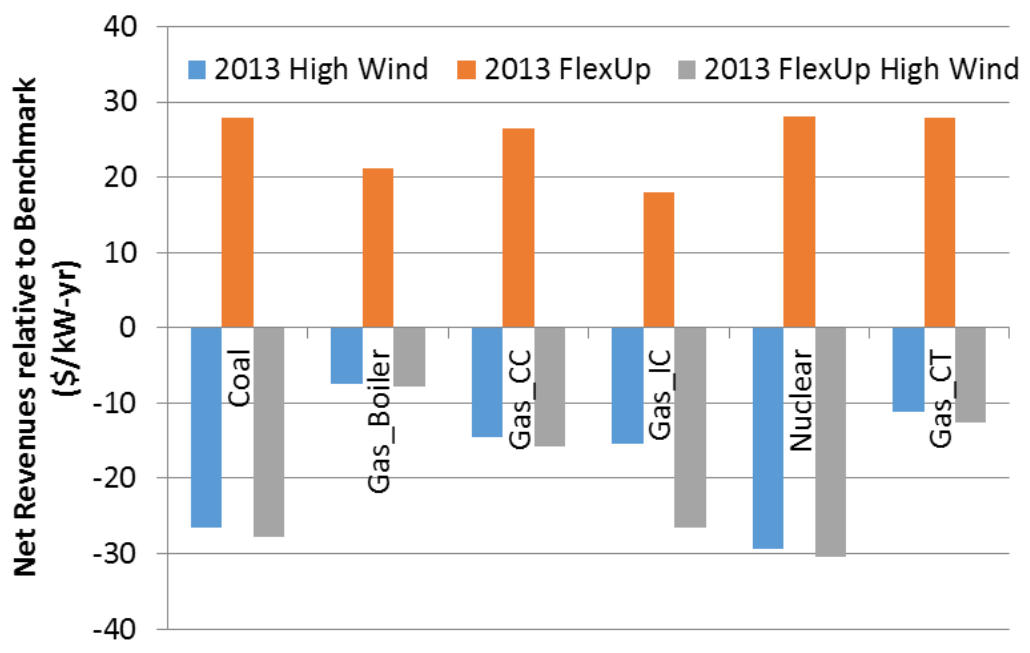

Figure 19. Net revenues difference from the 2013 Benchmark scenario 
As shown in Figure 20, the contribution from all reserves constituted a very small fraction of the total revenues, roughly $4 \%-5 \%$ for the 2013 Benchmark and Flex Up scenarios. This is consistent with values indicated by Figure 1 in the 2013 State of the Market Report (Potomac Economics 2014). The dominant share of revenues came from energy. Figure 20 also reveals that the impact of additional reserve requirements in the Flex Up scenario increased both the reserve and energy revenue streams - by approximately $44 \%$ and $13 \%$, respectively — relative to the Benchmark scenario in 2013.

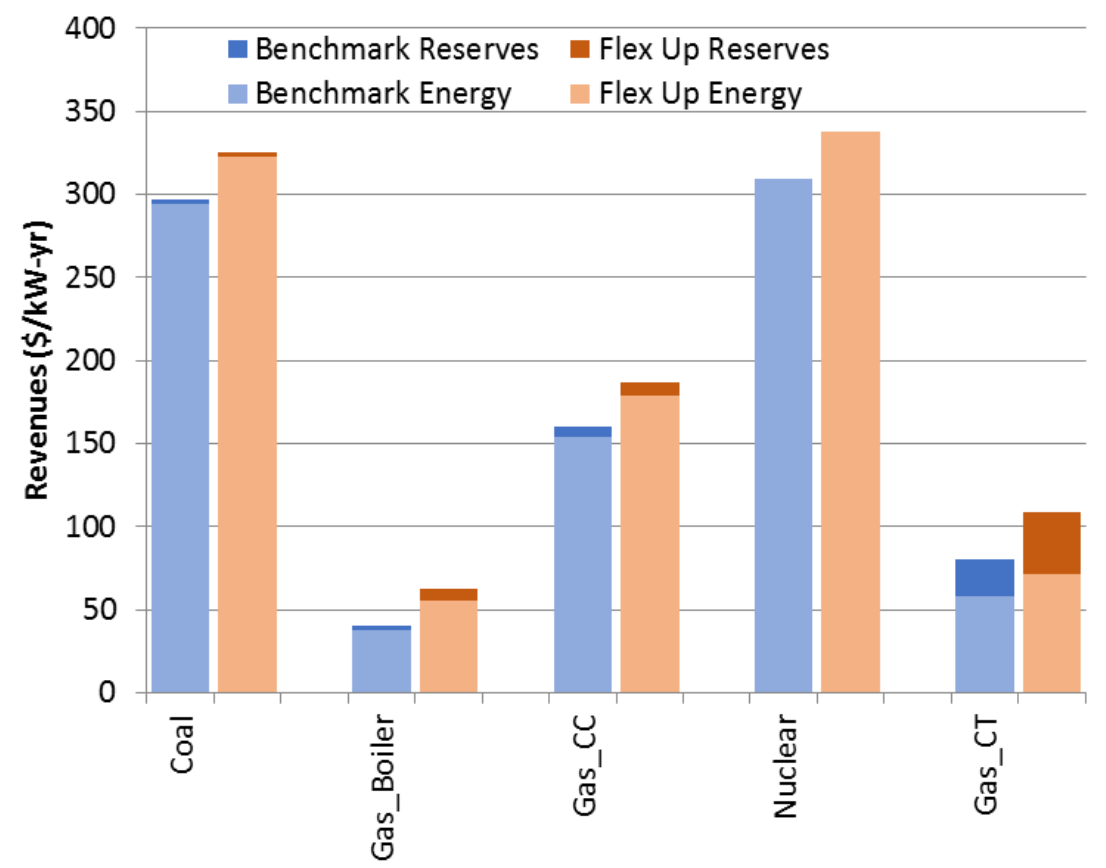

Figure 20. Total revenues for the 2013 Benchmark and Flex Up scenarios

Results from the Retire 4GW Coal sensitivity scenario have important scarcity pricing and resource adequacy implications. In the model used in this study, a load penalty price curve was used as a proxy generator for demand response, which also reflects potential scarcity pricing and resource adequacy problems. This proxy generator was used to help find a feasible solution in a reasonable amount of time, and it added a penalty on the power balance constraint slack variable in the mixed-integer programming formulation. This methodology was implemented by Townsend (2013) to reflect ERCOT's use of a multitiered power balance penalty function with prices that increase as the energy imbalance increases (ERCOT 2013b).

These price penalties drove the significant increase in net revenue results for the Retire 4GW Coal scenario shown in Figure 18. However, the exact revenues are heavily dependent on this price curve input; consequently, results should be interpreted as qualitative only. Table 14 reveals a significant increase in the occurrence of this load penalty price with the Retire $4 \mathrm{GW}$ Coal scenario relative to the Benchmark scenario for all 3 years. The declining frequency of the penalty price events across the 3 years in Table 14 is also consistent with reductions in the frequency of ERCOT's scarcity pricing (Potomac Economics 2015). 
Table 14. Frequency of Penalty Price among All Four Regions

\begin{tabular}{lll}
\hline & $\begin{array}{l}\text { Benchmark } \\
\text { Scenario }\end{array}$ & $\begin{array}{l}\text { Retire 4GW Coal } \\
\text { Scenario }\end{array}$ \\
\hline $\mathbf{2 0 1 2}$ & 172 & 546 \\
$\mathbf{2 0 1 3}$ & 154 & 416 \\
$\mathbf{2 0 1 4}$ & 8 & 164 \\
\hline
\end{tabular}

\subsection{Reliability Metrics}

With the growth in renewable energy sources, utilities face challenges in determining appropriate metrics to evaluate their system capacity and reliability. The most common reliability metrics are represented by the loss-of-load probability, loss-of-loud-hours (LOLH), and expected unserved energy (EUE). Another important metric that has been used as a reference for many years to estimate whether utilities had to invest in new generation capacity is the planning reserve margin. In the case of ERCOT, following the suggestions from Brattle (Newell et al. 2014) to use the EUE as a reliability metric, the Public Utility Commission of Texas has had open meetings during which the use and appropriateness of the EUE compared to the standard loss-ofload expectation (LOLE) metrics have been discussed (NERC 2014).

Newell et al. (2014) used a normalized EUE as an alternative to the 1-in-10 standard that a NERC task force recently recommended to address the limitations of traditional 1-in-10 LOLE and LOLH standards. This normalized EUE refers to the total annual MWh of firm energy expected to be shed, divided by the total MWh of annual system load, and it represents the percentage of system load that cannot be served due to supply shortages. Some European markets as well as the Australian Energy market already use normalized EUE to set minimum reliability thresholds.

A detailed study of the system reliability and planning reserve margins in the ERCOT interconnection as well as each of the hubs is beyond the scope of this study. Future work will provide more insights into how current reliability metrics might be impacted by revenue insufficiency. 


\section{Conclusions}

This paper estimated the missing money problem using a production cost model of an ERCOTlike system for the years 2012-2014 and studied how different ancillary service products, wind penetration levels, and generator fleet compositions can affect both net revenues and market outcomes. The production simulation analysis provides insights into the missing money problem primarily through the net revenue outputs. The net revenues for all cases (except when significant levels of coal units are retired) were insufficient to justify investments in new capacity. This was true for all five key generation types that represented capital-intensive technologies (e.g., nuclear, coal) as well as peak technologies (e.g., gas-fired CTs).

Market participants' strategic bidding behaviors were reproduced by applying different sets of markups to the true production costs of all gas generators. These gas units are the most prominent generators in the ERCOT market, and thus they impact the prices received by all generators. This methodology improved upon traditional production cost modeling activities by incorporating a proxy for strategic behavior in generator offers. Next, we tested the impact of these markups on revenue sufficiency with respect to changes in the generation fleet and ancillary service products offered in the market. Larger wind penetrations depressed prices and also revenues, thereby exacerbating the missing money problem. Adding an ancillary service product, in the form of a flexible reserve requirement, marginally reduced the revenue sufficiency challenges; the inclusion of this reserve product increased both energy and reserve revenues, highlighting the linkage between these two system components. Retiring a large fraction of the existing coal fleet increased the frequency of scarcity-like pricing events, leading to larger revenues. Therefore, this scenario saw only limited revenue sufficiency challenges. However, all other scenarios, including those with an ancillary service product and higher wind penetration levels, yielded revenue sufficiency shortfalls in this test model system.

Results have shown that when generators use markups, they can raise both system costs and consequently the revenues that they receive from the market. However, net revenues may increase or decrease depending on the technology and the year under study. Results also show that when production cost models are used out of the box, they do not capture prices accurately. Thus, proxies for market participant behavior (e.g., markups) are needed to better represent how electricity markets work.

Estimating the extent of the missing money problem in current electricity markets is an important and nontrivial task that requires representing both how the power system operates and how market participants behave. This study is the first step in a much larger NREL research program to investigate the market impacts of high penetrations of variable generation. Future analyses of electricity markets using production cost models are needed to study how wholesale electricity markets will evolve under increasing penetration levels of renewables. In particular, future studies should better represent the ERCOT system at a finer spatial and temporal resolution, incorporate unit commitment and real-time dispatch components with explicit treatment of variable generation uncertainty due to forecast error, use a nodal approach, include demand-side participation, include maintenance and outage rates, account for self-scheduled and bilateral agreements, include uplift/mark-whole payments, and implement current and/or proposed market design rules that specifically target scarcity pricing and the missing money problem (e.g., the operating reserve demand curve, or ORDC, rule). Future studies should also reproduce in a more 
realistic fashion how market participants behave and adapt to current and proposed new market design rules and increase renewable penetrations - for example, by using an agent-based modeling approach. 


\section{References}

Anderson, K. 2015. "RE: Notice of Proposed Order and Request for Comment on an Application for an Exemptive Order From Southwest Power Pool, Inc. From Certain Provisions of the Commodity Exchange Act Pursuant to the Authority Provided in Section 4(c)(6) of the Act." http://www.puc.texas.gov/agency/about/commissioners/anderson/letters/PUCT_Comments_Reg arding_SPP_Exemptive_Order.pdf.

AWS Truepower. 2015. "Simulations of Wind Generation Patterns for the ERCOT Service Area” (Technical Memo). Albany, NY.

Blair, N., K. Cory, M. Hand, K. Parkhill, B. Speer, T. Stehly, and D. Feldman. 2015. “Annual Technology Baseline," Presented July 8, 2015. http://www.nrel.gov/docs/fy15osti/64077.pdf.

Cohen, S. M. 2012. "A Techno-economic Plant- and Grid-Level Assessment of Flexible $\mathrm{CO}_{2}$ Capture." PhD Dissertation, The University of Texas at Austin.

Cramton, P. 2003. "Electricity Market Design: The Good, the Bad, and the Ugly." Proceedings of the IEEE 36th Annual Hawaii International Conference on System Sciences. Piscataway, NJ: Institute of Electrical and Electronics Engineers.

Cramton, P., and S. Stoft. 2006. "The Convergence of Market Designs and Adequate Generating Capacity." White paper for the Electricity Oversight Board.

ECCO International. 2015. Modeling and Analysis of Wholesale Electricity Market Design: Understanding the Missing Money Problem (Subcontract Report). NREL/SR-5D00-64255. Golden, CO: National Renewable Energy Laboratory.

EIA. 2012. "Texas Natural Gas Price Sold to Electric Power Consumers.”

EIA, 2013a. "Form EIA-860 detailed data." Accessed March 2016:

https://www.eia.gov/electricity/data/eia860/

EIA, 2013b. "Form EIA-923 detailed data." Accessed March 2016: https://www.eia.gov/electricity/data/eia923/

Ela, E., M. Milligan, A. Bloom, A. Botterud, A. Townsend, and T. Levin. 2014. Evolution of Wholesale Electricity Market Design with Increasing Levels of Renewable Generation (Technical Report). NREL/TP-5D00-61765. Golden, CO: National Renewable Energy Laboratory.

ERCOT. 2011. "ERCOT Long-Term Study Task Force Meeting May 3, 2011.”

ERCOT. 2012-2014a. "Historical DAM Load Zone and Hub Prices." Accessed December 2015: http://mis.ercot.com/misapp/GetReports.do?reportTypeId=13060\&reportTitle=Historical\%20DA M\%20Load\%20Zone\%20and\%20Hub\%20Prices\&showHTMLView=\&mimicKey 
ERCOT. 2012-2014b. "Historic DAM Clearing Prices for Capacity." Accessed December 2015: http://mis.ercot.com/misapp/GetReports.do? reportTypeId=13091\&reportTitle=Historical\%20DA M\%20Clearing\%20Prices\%20for\%20Capacity\&showHTMLView=\&mimicKey

ERCOT. 2013a. "Houston Import Project-ERCOT Update." Presented at the RPG Meeting, December 17, 2013. Accessed November 2015: http://www.ercot.com/content/meetings/rpg/keydocs/2013/1217/Houston_Import_Project_Study ERCOT Update RPG-12-17-2013.pdf.

ERCOT. 2013b. Setting the Shadow Price Caps and Power Balance Penalties in Security Constrained Economic Dispatch (Technical Report). Austin, TX. Accessed December 2015: http://www.ercot.com/content/meetings/board/keydocs/2013/0514/2.2_Methodology_for_Setting the Shadow Price Caps and Power.pdf.

ERCOT. 2014. Impacts of Environmental Regulations in the ERCOT Region (Technical Report). Austin, TX. Accessed May 2016:

http://www.ercot.com/content/news/presentations/2014/Impacts $\% 20$ of $\% 20$ Environmental $\% 20 \mathrm{Re}$ gulations $\% 20$ in $\% 20$ the $\% 20$ ERCOT $\% 20$ Region.pdf.

ERCOT. 2015. ERCOT Analysis of the Impacts of the Clean Power Plan: Final Rule UpdateOctober 16, 2015 (Technical Report). Austin, TX. Accessed December 2015:

http://www.ercot.com/content/news/presentations/2015/ERCOT_Analysis_of the_Impacts_of t he_Clean_Power_Plan-Final_.pdf.

Gallo, G. 2016a, "An Integrated Agent-Based and Production Cost Modeling Framework for Renewable Energy Studies," 2016 49th Hawaii International Conference on System Sciences (HICSS), Koloa, HI, 2016, pp. 2390-2399. doi: 10.1109/HICSS.2016.299

Gallo, G., 2016b. Electricity Market Games: How Agent-Based Modeling Can Help under High Penetrations of Variable Generation, Elec Jour. 29 (2016) pp. 39-46, 10.1016/j.tej.2016.02.001

Ibanez E., and M. Milligan. (2012). "Impact of Transmission on Resource Adequacy in Systems with Wind and Solar Power." Presented at the IEEE Power\& Energy Society General Meeting, San Diego, California, July 22-26, 2012. http://www.nrel.gov/docs/fy12osti/53482.pdf.

Keane, A., M. Milligan, C.J. Dent, B. Hasche, C. D'Annunzio, K. Dragoon, H. Holttinen, N. Samaan, L. Soder, and M. O’Malley. 2011. "Capacity Value of Wind Power." IEEE Transactions on Power Systems 26(2):564-572, May. doi: 10.1109/TPWRS.2010.2062543.

Levin T. and Botterud A., "Capacity Adequacy and Revenue Sufficiency in Electricity Markets with Wind Power," IEEE Transactions on Power Systems, vol. 30, no. 3, pp. 1644-1653, May 2015. doi: 10.1109/TPWRS.2015.2403714

Lew, D., G. Brinkman, E. Ibanez, A. Florita, M. Heaney, B.-M. Hodge, M. Hummon, G. Stark, J. King, S.A. Lefton, N. Kumar, D. Agan, G. Jordan, and S. Venkataraman. 2013. The Western Wind and Solar Integration Study Phase 2 (Technical Report). NREL/TP-5500-55588. Golden, CO: National Renewable Energy Laboratory. Accessed October 7, 2013: http://www.nrel.gov/docs/fy13osti/55588.pdf. 
Milligan, M., H. Holttinen, L. Soder, and C. Clark. 2012. "Market Structures to Enable Efficient Wind and Solar Power Integration." Proceedings of the 2012 IEEE Power and Energy Society General Meeting, San Diego, California, July 22-26, 2012,. Piscataway, NJ: Institute of Electrical and Electronics Engineers, 6.

NERC. 2014. 2014 Long-Term Reliability Assessment: November 2014 (Technical Report). Atlanta, GA. Accessed December

2015: http://www.nerc.com/pa/RAPA/ra/Reliability\%20Assessments\%20DL/2014LTRA_ERAT TA.pdf.

Newell, S.A., K. Spees, J.P. Pfeifenberger, I. Karkatsouli, N. Wintermantel, and K. Carden. 2014. Estimating the Economically Optimal Reserve Margin in ERCOT (Technical Report). Austin, TX: Public Utility Commission of Texas. Accessed December 2015: http://www.brattle.com/system/publications/pdfs/000/004/978/original/Estimating the Economi cally_Optimal_Reserve_Margin in_ERCOT_Revised.pdf?1395159117.

Potomac Economics, LTD. 2004. 2004 Assessment of the Operation of the ERCOT Wholesale Electricity Markets (Technical Report). Fairfax, VA. Accessed November 2015: http://www.puc.texas.gov/industry/electric/reports/ERCOT_annual_reports/special/ERCOT_Op Rpt_Potomac_Eco.pdf.

Potomac Economics, LTD. 2013. 2012 State of the Market Report for the ERCOT Wholesale Electricity Markets (Technical Report). Accessed November 2015: https://www.potomaceconomics.com/uploads/ercot_reports/2012_ERCOT_SOM_REPORT.pdf.

Potomac Economics, LTD. 2014. 2013 State of the Market Report for the ERCOT Wholesale Electricity Markets (Technical Report). Fairfax, VA. Accessed December 2015: https://www.potomaceconomics.com/uploads/ercot_documents/2013 ERCOT_SOM REPORT. pdf.

Potomac Economics, LTD. 2015. 2014 State of the Market Report for the ERCOT Wholesale Electricity Markets (Technical Report). Fairfax, VA. Accessed December 2015:

https://www.potomaceconomics.com/uploads/ercot_documents/2014 ERCOT_State of the Ma rket_Report.pdf.

Townsend, A. 2013. "A Grid-Level Assessment of Compressed Air Energy Storage in ERCOT." $\mathrm{PhD}$ Dissertation, The University of Texas at Austin.

Ventyx. 2015. Velocity Suite Database. Atlanta, GA: Ventyx/ABB. Accessed December 2015. 


\section{Appendix: Additional Benchmarking and Revenue Sufficiency Results}

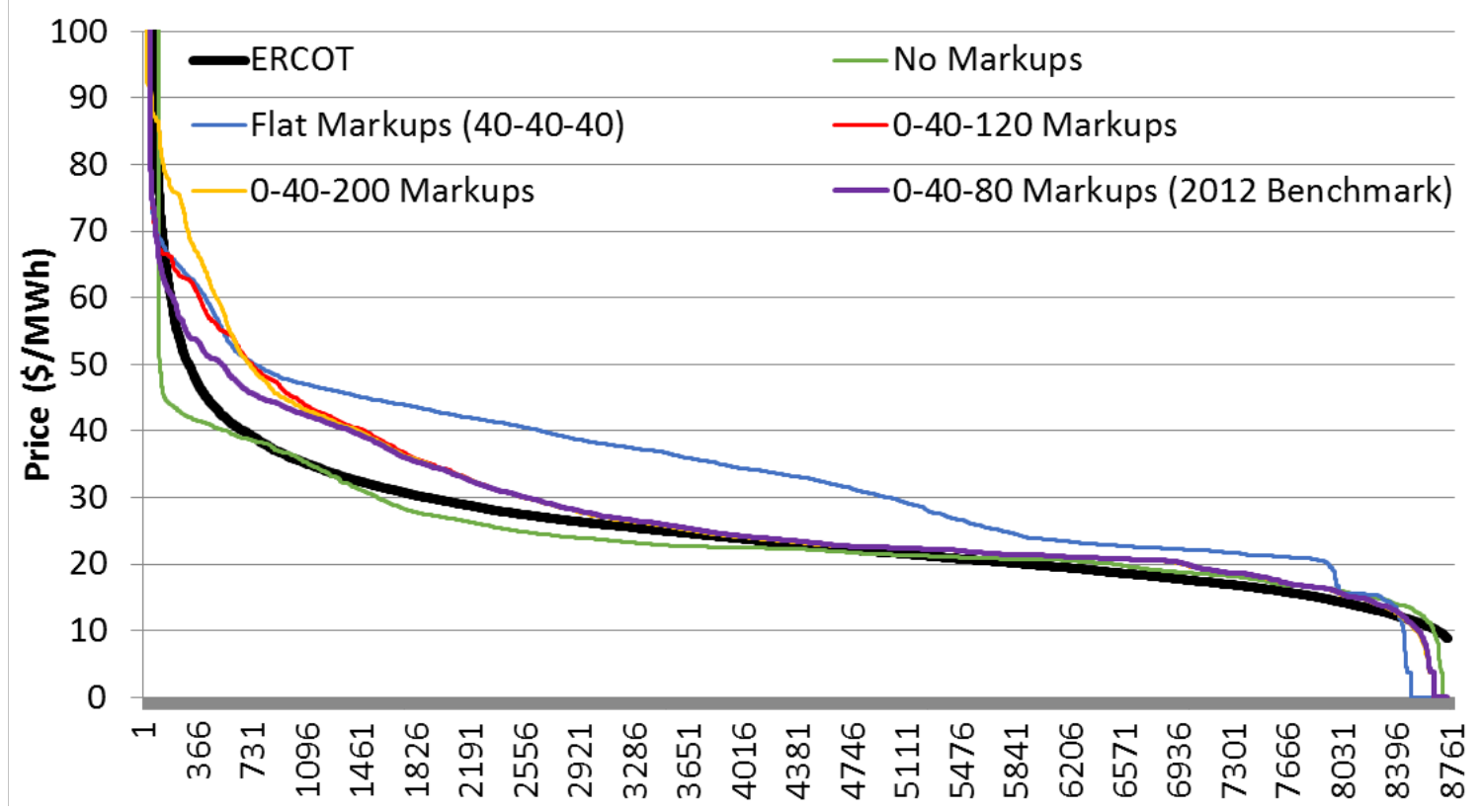

Figure 21. Day-ahead price duration curves averaged across all regions (magnified to show prices at or below \$100/MWh) for all 2012 markup scenarios and historic day-ahead SPPs from ERCOT

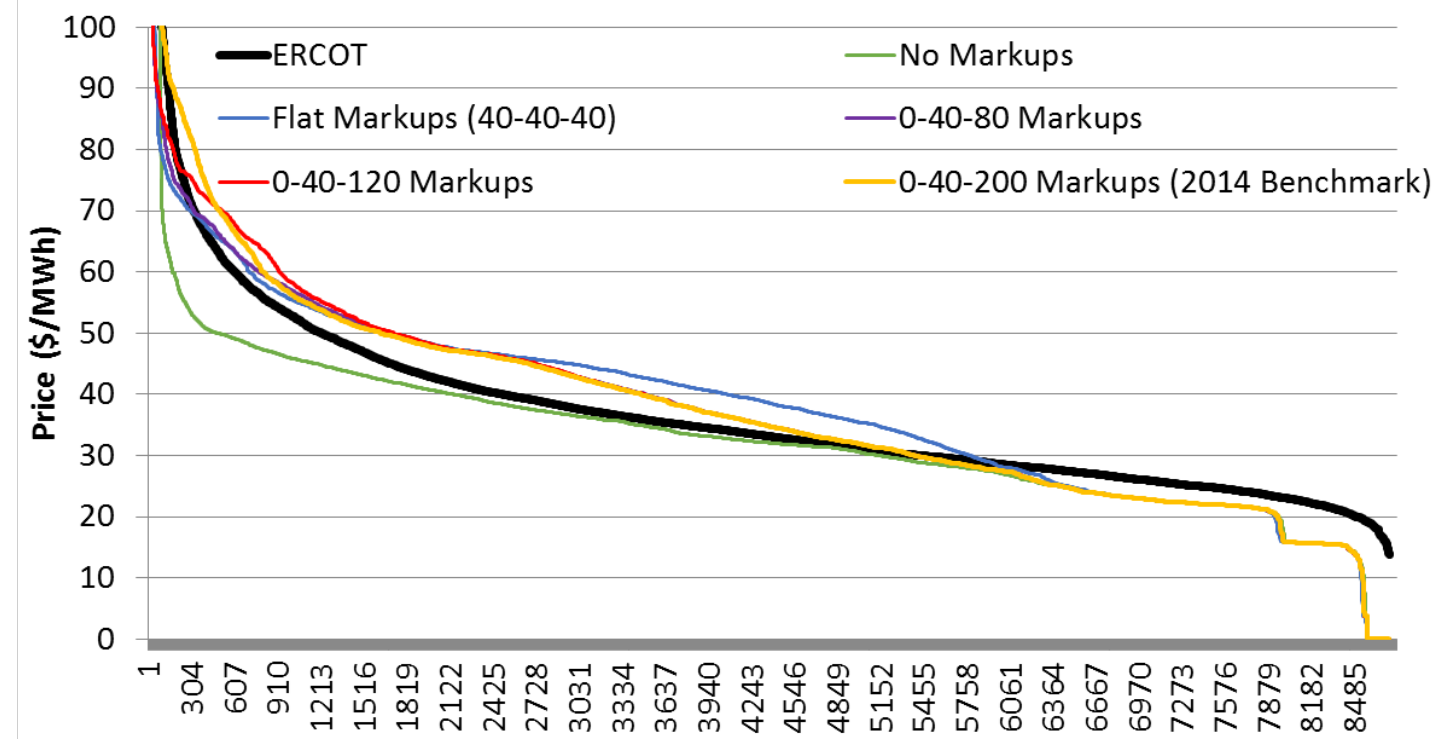

Figure 22. Day-ahead price duration curves averaged across all regions (magnified to shows prices at or below \$100/MWh) for all 2014 markup scenarios and historic day-ahead SPPs from ERCOT 
Table 15. Benchmark Scenarios Net Revenues with and without Start-up and Shutdown Costs (S\&S) and Compared to Annualized Investment Costs from the NREL's ATB and ERCOT's State of the Market (SOM) Reports

\begin{tabular}{lccccc}
\hline & Coal & $\begin{array}{c}\text { Gas } \\
\text { Boiler }\end{array}$ & Gas CC & Nuclear & Gas CT \\
\hline $\begin{array}{l}\text { 2012 Benchmark } \\
\text { Net Revenue with S\&S }\end{array}$ & 100 & 46 & 73 & 216 & 30 \\
$\begin{array}{l}\text { 2012 Benchmark Net } \\
\text { Revenue without S\&S }\end{array}$ & 99 & 43 & 71 & 216 & 26 \\
\hline $\begin{array}{l}\text { 2013 Benchmark } \\
\text { Net Revenue with S\&S }\end{array}$ & 117 & 16 & 42 & 233 & -3 \\
\hline $\begin{array}{l}\text { 2013 Benchmark Net } \\
\text { Revenue without S\&S }\end{array}$ & 116 & 12 & 39 & 233 & -6 \\
\hline $\begin{array}{l}\text { 2014 Benchmark } \\
\text { Net Revenue with S\&S }\end{array}$ & 146 & 11 & 34 & 264 & -15 \\
\hline $\begin{array}{l}\text { 2014 Benchmark Net } \\
\text { Revenue without S\&S }\end{array}$ & 146 & 6 & 30 & 264 & -19 \\
\hline $\begin{array}{l}\text { NREL 2015 ATB } \\
\text { Annualized CAPEX (2013\$) }\end{array}$ & 306 & 91 & 91 & 576 & 77 \\
\hline $\begin{array}{l}\text { 2012 ERCOT SOM } \\
\text { 2013 ERCOT SOM }\end{array}$ & 35 & 25 & 42 & 134 & 25 \\
\hline \begin{tabular}{l} 
2014 ERCOT SOM \\
\hline
\end{tabular} & 105 & 37 & 57 & 227 & 37 \\
\hline
\end{tabular}

